\title{
Statistical analysis of equatorial plasma irregularities retrieved from Swarm 2013-2019 observations
}

Ercha Aa, ${ }^{1,2}$ Shasha Zou, ${ }^{1}$ and Siqing Liu ${ }^{3}$

Correspondence to: E. Aa (aercha@mit.edu)

${ }^{1}$ Department of Climate and Space

Sciences and Engineering, University of

Michigan, Ann Arbor, MI, USA.

${ }^{2}$ Now at Haystack Observatory,

Massachusetts Institute of Technology,

Westford, MA, USA.

${ }^{3}$ National Space Science Center, Chinese

Academy of Sciences, Beijing, China.

This is the author manuscript accepted for publication and has undergone full peer review but has not been through the copyediting, typesetting, pagination and proofreading process, which may lead to differences between this version and the Version of Record. Please cite this article as doi: 10.1029/2019JA027022 
3 Abstract. In this study, we present a statistical analysis of equatorial 4 plasma irregularities (EPIs) by using in-situ plasma density measurements 5 of the Swarm constellation from December 2013 to December 2019. The occurrence patterns for both postsunset and postmidnight EPIs with respect to longitude, season, local time, latitude, solar activity, and geomagnetic activity level are investigated, respectively. The main findings are as follows: (1) The postsunset/postmidnight EPIs occurrence rates exhibit different longitudinal and seasonal dependence: the postsunset EPIs have the maximum occurrence rate over the American-Atlantic sectors during the December solstice and equinoxes, and the postmidnight EPIs have the maximum occurrence rate during the June solstice, especially over the African sector. (2) The postsunset EPIs occurrence rates have a positive correlation with solar activity, while the postmidnight EPIs are negatively correlated with it. (3) The latitudinal distribution of EPIs exhibits a double-peak structure around $\pm 5^{\circ}$ magnetic latitude with a more significant peak in the summer hemisphere.

(4) The EPIs occurrence rate increases with increasing geomagnetic activity level. (5) The main controlling factors for the distribution of postsunset EPIs are the magnetic declination angle, equatorial vertical $\mathrm{E} \times \mathrm{B}$ drift, and thermospheric zonal wind. For the postmidnight EPIs, the main controlling factors are likely to be atmospheric gravity waves and equatorward thermospheric meridional wind associated with midnight temperature maximum. 


\section{Introduction}


45 
91 


\section{Data and Method}

The Swarm constellation consists of three satellites, which were launched into an approximately circular near-polar orbit $\left(\sim 88^{\circ}\right)$ on 22 November 2013. Swarm A and Swarm C fly side-by-side at an altitude of 440-460 km, separated by about $1.4^{\circ}$ in longitude. The third satellite, Swarm B, orbits the Earth at about $520 \mathrm{~km}$ with a higher inclination. This provides an opportunity to make a comparative analysis of ionospheric irregularities by using similar $N e$ measurements from identical instruments at different altitudinal/longitudinal sectors. Swarm has comprehensive payload elements: vector field magnetometer, absolute scalar magnetometer, electric field instrument, accelerometer, laser range reflector, and GPS receiver. One of the most relevant instruments onboard is the electric field instrument (EFI) that is capable of measuring the plasma density with a time resolution of $2 \mathrm{~Hz}$, which affords an excellent opportunity to study the variability and distribution of plasma irregularities.

Different algorithms have been used for extracting the EPI events from the $N e$ measurements, and we use a similar method to that described by Xiong et al. [2016], Stolle et al. [2006], Wan et al. [2018] and references therein. First, the continuous time series of Ne profiles, after quality control flags were applied, were divided into orbital segments of equatorial crossing within a range of $\pm 40^{\circ}$ geomagnetic latitude. Then the log electron density of each orbital segment was high-pass filtered with a cutoff period of $40 \mathrm{~s}$ that corresponds to an along-track spatial scale of $\sim 300 \mathrm{~km}$. Subsequently, the filtered residual was rectified. Residual values exceeding a threshold were identified as the EPIs events. Since there is no generally accepted value of the threshold, after estimating the level of quiet-time $N e$ variations and considering the previous references [e.g. Su et al., 2006; Kil 


\section{Statistical Results}

\subsection{Longitudinal and Seasonal Distribution}




\section{.}

in longitudes between $-60^{\circ}$ and $30^{\circ}$, while relatively fewer irregularities are located over the Asian sector. In the postmidnight sector, the Atlantic and African sectors still have higher occurrence rates; However, the Asian and Pacific sectors have more EPIs events than the postsunset case, and the amplitude of irregularities can be substantial (i.e., two orders of magnitudes change) over these sectors. This implies that the highest occurrence rate does not always coincide with the largest depletion amplitude, which is similar to the results in Wan et al. [2018].

To further specify the seasonal variation of the plasma irregularities, Figure 3 shows the global distribution and the longitudinal distribution of the occurrence rate of EPIs for all-season, the December solstice, the March/September equinoxes, and the June solstice, respectively. The gridded occurrence rates shown in Figures 3a, 3c, 3e, and 3g were calculated as the ratio of the detected EPI numbers to the satellite crossing counts in each bin. The 1D occurrence rate shown in Figures 3b, 3d, 3f, and 3h is calculated as the ratio of the number of orbits in which EPIs were detected divided to the total number of orbits in each longitudinal band. The all-season result of Figure 3a exhibits that the occurrence rate has much higher values over the African-Atlantic-South American regions, which has a similar longitudinal and latitudinal distribution pattern with those indicated in Figure 2. However, there are distinct variations in the distribution pattern of different seasons. Near the December solstice, the density irregularity is more frequently detected over the South American sector $\left(60^{\circ} \mathrm{W}-30^{\circ} \mathrm{W}\right)$ with the occurrence rate ranging from $40 \%$ 80\%. For the March/September equinoxes, the longitudinal preference of EPIs extends to the Atlantic and west African sectors $\left(45^{\circ} \mathrm{W}-15^{\circ} \mathrm{E}\right)$, while the occurrence rate over these region reduces to $30 \%-50 \%$. As for the June solstice, the distribution is relatively even 
with broader longitude coverage, and the peak of occurrence rate shifts to the African sector.

Figures $4 \mathrm{a}$ and $4 \mathrm{~b}$ show the seasonal-longitudinal distribution of the occurrence rate of EPIs during postsunset and postmidnight periods, respectively. The resolution is $10^{\circ}$ in longitude and half a month in time, and the occurrence rate is normalized by the number of satellite crossings as shown in Figures $4 \mathrm{c}$ and $4 \mathrm{~d}$. For the postsunset period, the monthly occurrence pattern shows larger values near the two equinoxes: one in FebruaryMarch and another one in October-November. In both season there is a clear longitudinal preference for the Atlantic-American sector. Moreover, the postsunset occurrence rate of EPIs was lower during the periods of May-September; the irregularity signature is severely suppressed in the Atlantic-American sector, but mainly confined within the African and Pacific regions, which is consistent with those indicated in Stolle et al. [2006]. On the other hand, during the postmidnight period, the distribution pattern exhibits the opposite feature: the region of high occurrence rate shifts longitudinally from the Atlantic to the African sector around June solstice and to the Pacific sector around the December solstice, while the occurrence rate around the equinoxes is substantially reduced. One thing worth noting is that the Swarm constellation does not have equal coverage of all spatial-temporal bins. For example, the postsunset period has less data availability around May/August and more availability around February, June, and November. The situation for the postmidnight is similar but shifted by a couple of months. This could make the above-mentioned statistical results have different uncertainty variations. Thus, the error bars showing possible biases due to the uneven data coverage are introduced here, which 
can be calculated as follows:

$\sigma=\sqrt{\frac{f \times(1-f)}{N-1}}$

where $\sigma$ is the uncertainty, $f$ is the occurrence rate, and $N$ is the total number of satellite pass for each given bin.

Figure 5 shows the monthly variation of the occurrence rate of EPIs during the postsunset and postmidnight periods for four different longitudinal sectors: America-Atlantic $\left(100^{\circ} \mathrm{W}-20^{\circ} \mathrm{W}\right)$, Africa $\left(20^{\circ} \mathrm{W}-60^{\circ} \mathrm{E}\right)$, Asia $\left(60^{\circ} \mathrm{E}-140^{\circ} \mathrm{E}\right)$, and Pacific $\left(140^{\circ} \mathrm{E}-100^{\circ} \mathrm{W}\right)$. The bin size is half a month, and the distribution pattern has a clear seasonal preference: the postsunset EPIs are often observed during equinoxes, while the postmidnight EPIs mainly occur around solstices. From the spatial perspective, the longitudinal difference can be viewed more clearly. In the American-Atlantic sectors, the occurrence rate during the December solstice and equinoxes is reduced from postsunset $(30 \%-40 \%)$ to postmidnight (5\%-15\%), while a considerable enhancement can be observed during the June solstice from postsunset ( $5 \%)$ to postmidnight (15\%-20\%). In the African sector, the situation is slightly different: the postsunset EPIs have a lower occurrence level (10\%-20\%) and two minor peaks near equinoxes. While the postmidnight EPIs have the most significant occurrence rate around the Northern Hemisphere summer solstice (20\%$35 \%$ ) compared with the other longitudinal sectors. In the Asian and Pacific sectors, the general occurrence rate of postsunset EPIs is low, but the occurrence rate of the postmidnight EPIs exhibits a considerable enhancement during the June solstice for the Asian longitudes, and also during the December solstice at the Pacific longitudes. 


\section{2. local Time and Latitudinal Variation}

36

Figure 6 shows the longitudinal-local time distribution of the occurrence rate of EPIs for different seasons with a resolution of $10^{\circ}$ in longitude and 1 hour in local time. The occurrence rate is calculated as the ratio of the detected EPI numbers to the satellite crossing counts in each bin. Figure 7 further displays the occurrence rate variations as a function of local time at four different longitudinal sectors with error bars reflecting the uncertainty. In both Figures 6 and 7, it can be seen that EPI is basically a nighttime phenomenon with a significant occurrence rate peak around 20-21 LT during the December solstice and the equinoxes. The postsunset prereversal enhancement (PRE) of an eastward electric field is one of the most important generation mechanisms of plasma irregularities [Eccles et al., 2015], which can increase the equatorial upward drift velocity and provide a favorable condition for the R-T instability to develop. Thus the occurrence rate of EPI usually reaches a peak after sunset. However, during the June solstice, the EPIs are more frequently observed in the postmidnight sector, especially over the African longitudes, with a maximum occurrence rate around 03-04 LT reaching 25\%-30\%. This phenomenon is consistent with previous studies [e.g. Dao et al., 2011; Yizengaw et al., 2013], though the mechanisms for generating the postmidnight EPI peak are still unknown and widely debated. We will further discuss this topic in the discussion section.

In addition to the local time variations, it is also important to investigate the latitudinal dependence of the occurrence rate of EPIs. Considering the characteristics of EPIs are influenced by both the geomagnetic field configuration and the spinning of the Earth, we here adopted the coordinated system of magnetic latitude (MLAT) and magnetic local time (MLT) to do the analysis. Figures $8 \mathrm{a}-8 \mathrm{c}$ show the MLAT-MLT distribution of the 
occurrence rate of EPIs for different seasons with a resolution of $2^{\circ}$ in magnetic latitude and 1 hour in magnetic local time. Moreover, the corresponding latitudinal variation for postsunset (Figures 8d-8f) and postmidnight (Figures $8 \mathrm{~g}-8 \mathrm{i}$ ) sectors are displayed, respectively. The latitudinal distribution exhibits a double-peak structure that can be fitted roughly by a bimodal distribution curve. The occurrence peaks are centered in two latitudinal bands north and south of the equator that is located approximately at $\pm 5^{\circ}$, which is similar with previous studies [Stolle et al., 2006; Xiong et al., 2010, 2012]. One thing worth noting is that the northern peak is slightly higher than the southern peak during the June solstice and equinoxes in both local times, while the situation is reversed during the December solstice. It is known that the trans-equatorial wind may cause a decrease in the local conductivity on the upwind side (summer hemisphere) where the layer is raised, and cause an increase in the local conductivity on the downwind side (winter hemisphere) where the layer is lowered. The latter effect is typically stronger than the former one due to the height-dependent ion composition, so there is a net increase in the total field-line integrated conductivity [Maruyama, 1988; Huba and Krall, 2013; Abdu, 2019]. As a result, the nonlinear growth rate of the R-T instability will be suppressed in both hemispheres mainly due to the enhanced winter hemisphere conductivity. Moreover, in the winter hemisphere of high conductivity, polarization electric fields in the F-region with smaller scales may be shorted out [Pudovkin, 1974; Huang, 2016], so that the instabilities for density irregularities near the bubble boundaries may be suppressed. This might contribute to the slightly lower occurrence rate of the irregularities in the winter hemisphere. More future work needs to be performed to further the understanding on this subtle asymmetry. 


\subsection{Dependence on Solar and Geomagnetic Activity}

The Swarm measurements used in the current study start from December 2013, close to the solar maximum of solar cycle 24, and continue to the deep solar minimum in December 2019. In order to present solar-cycle and solar activity dependence of EPIs, Figures 9a and $9 \mathrm{~b}$ show the multiyear longitudinal-monthly distribution of the EPI occurrence rate in the postsunset and postmidnight sectors with a resolution of $10^{\circ}$ in longitude and one month. The middle panels show the Swarm data coverage for each longitudinal-monthly bin. It can be seen that the crossing counts exhibit specific systematic pattern with a period of around four month, which is due to that the Swarm satellites need $\sim 120$ days to get full coverage of 24-hour local time [Lühr et al., 2016]. The seasonal and longitudinal variation of the occurrence rate is very similar with the global morphology shown in Figure 4: the postsunset EPIs have occurrence peak over the Atlantic-American sectors during the December solstice and equinoxes, while the postmidnight EPIs are most often observed in the African sector during the June solstice and in the Pacific sector during December solstice.

However, the solar activity dependence of the EPI occurrence rate in these two sectors exhibits opposite trends. As can be seen in Figure 9e and 9f, the postsunset EPIs have larger occurrence rate around solar maximum and gradually decrease with decreasing solar activity, but the occurrence rate of postmidnight EPIs exhibit a generally increasing trend with decreasing solar activity. Considering that the monthly data distribution is uneven due to the above-mentioned issue of local time coverage, this preliminary result of solar dependence needs to be further verified in a wider temporal window. Thus, Figures 10a and 10b show the scatter plots of triannual (four-month) averaged F10.7 index versus EPI 


\section{Discussion}

First of all, several studies have indicated that the smaller the angle between the equa- 
2004a, b; Otsuka, 2018]. At the South American and Atlantic longitudes, conditions for the minimum angle occur around February-March and October-November. This explains the more significant occurrence rates over these longitudinal sectors during the December solstice and equinoxes seasons as demonstrated in Figure 3. Moreover, the asymmetrical seasonal distribution seen during the December and the June solstice can also be explained by the inter-hemispheric winds that propagate from the summer hemisphere to the winter hemisphere [Burke et al., 2004a, b]. The R-T instability growth rate will be suppressed by the inter-hemispheric winds as stated in the previous section, which can result in a higher occurrence rate of plasma irregularities over the longitudes where the magnetic equator is located in the summer hemisphere, i.e., the African and Asian sectors in June-August, and the East Pacific and American sector in December-February.

Second, there is a significant postsunset/postmidnight distribution asymmetry as shown in Figure 4: the postsunset EPIs are often observed over the Atlantic-American sectors during the December solstice and equinoxes, while the postmidnight EPIs have a large occurrence peak around the June solstice, especially in the African sector. Besides the above-mentioned declination angle and inter-hemispheric meridional wind effects, the longitudinal feature of postsunset EPI is also related to the equatorial vertical plasma drift that influenced by the geomagnetic field morphology. The South Atlantic Anomaly (SAA) area has the weakest geomagnetic field strength comparing with an idealized dipole field, and the Earth's inner radiation belt also dips down to the height of the ionospheric Fregion [Abdu et al., 2005]. The $\mathrm{R}-\mathrm{T}$ growth rate in the postsunset sector is strongly dependent on the vertical component of equatorial plasma drift that is expressed as $V_{p}=\mathbf{E} \times \mathbf{B} / B^{2}$, where $\mathbf{E}$ is the zonal component of the electric field at the magnetic 
equator [Sultan, 1996]. Thus, assuming the postsunset zonal electric field is independent of longitude, the upward drift term in the growth rate calculation of R-T instability is favored in regions of low magnetic field intensity, especially in the area around the SAA [Burke et al., 2004a, b]. Although the actual variation of the upward plasma drift is more complicated, many statistical studies have found that the observed climatological pattern of EPIs is closely correlated with the longitudinal and seasonal variations of $V_{p}$ [e.g. $S u$ et al., 2008; Kil et al., 2009b; Carter et al., 2013; Yizengaw et al., 2014]. Moreover, the eastward thermospheric wind, combined with shear flow, is another important factor in controlling the occurrence of postsunset EPIs. Kudeki et al. [2007] indicated that the vertical Pedersen currents induced by eastward wind are able to polarize the initial density perturbation into an unstable mode to trigger plasma bubbles. Liu et al. [2016] found that the thermospheric zonal wind is strongest around equinoxes and weakest around June solstice, which agrees perfectly to the seasonal patterns of postsunset EPIs. Thus, the longitudinal and seasonal distribution of postsunset EPIs are mainly controlled by equatorial vertical drift and thermospheric zonal wind.

The formation mechanism of the postmidnight EPIs are still widely debated, which can be mainly attributed to either the continuation of EPIs generated in the premidnight hours [Bhattacharyya et al., 2001; Li et al., 2011], or irregularities freshly generated there owing to local plasma instabilities [Yizengaw et al., 2013; Huang et al., 2010]. The above-mentioned seasonal and longitudinal anomaly of the postmidnight EPIs could be generated by more than one factors considering the growth rate of R-T instability depends on various external driving forces, such as neutral wind, electric and magnetic field, as well as background ionospheric features, such as flux-integrated Pedersen conductivity 
and upward density gradient $[A b d u, 2001]$. Some studies found that the seasonal pattern of the F-layer altitude exhibit a noticeable midnight uplift, especially around the June solstice due to the equatorward meridional neutral winds that are associated with midnight temperature maximum [e.g. Nicolls et al., 2006; Yokoyama et al., 2011; Nishioka et al., 2012]. The uplift of the F-layer will cause a decrease in the ion-neutral collision frequency and thus increase the growth rate of the R-T instability. Furthermore, some other studies proposed that the localized gravity waves due to tropospheric convective activity near the intertropical convergence zone (ITCZ) could seed the bottomside irregularity to trigger the equatorial plasma bubbles, which might play a role in controlling the longitudinal dependence of EPIs since the convective process is more active over continental landmasses (especially for the African sector) than over the oceans [Yizengaw et al., 2013; Yizengaw and Groves, 2018]. Recently, Liu et al. [2017] conducted a systematic survey of medium-scale atmospheric gravity waves. They found that there are stronger perturbations over continents than over oceans, and the gravity wave activities maximize around June solstice and minimize around equinoxes. These gravity wave features highly resemble those of postmidnight EPIs indicated in our study. These points could possibly explain why the postmidnight EPIs are more often observed during the June solstice and over the African sector, though more extensive evidence is still needed.

Last but not least, the role of solar and geomagnetic activities in the EPI occurrence rate needs to be further specified. Many previous studies have seemingly conflicting results of the solar activity dependence as we described in the introduction part. In the current study, opposite solar activity dependencies were discovered for the postsunset and postmidnight EPIs. In order to further validation this opposite solar cycle dependence, 


\section{wes}

we here also used the in situ ion density data from the Ion Velocity Meter onboard the Communications/Navigation Outage Forecasting System (C/NOFS) from August 2008 to November 2015 to conduct a similar solar dependence study. C/NOFS has a low Earth orbit with a $13^{\circ}$ inclination, a perigee near $400 \mathrm{~km}$, and an apogee near $850 \mathrm{~km}$. The same algorithm specified in section 2 is applied to C/NOFS in situ ion density with a time cadence of $1 \mathrm{~Hz}$. Figure 11 shows the solar cycle dependence of EPIs by using C/NOFS data, which has the same feature with those of Swarm result that the postsunset EPI is positively correlated with the F10.7 index, and the postmidnight EPI is negatively correlated with F10.7 index. So the contradictory results could be depending on whether the majority of the EPI events in their database is in the postsunset or postmidnight sector. However, a new question is also raised: why the postmidnight EPIs exhibit a different solar activity dependence pattern? Otsuka [2018] analyzed the $g / \nu_{i n}$ term in the linear growth rate of the R-T instability, where $g$ is the gravity acceleration and $\nu_{i n}$ is the ion-neutral collision frequency. This term is larger during the nighttime than the daytime, and increases with decreasing solar activity since the collision frequency $\nu_{i n}$ is proportional to the neutral density, which is lower during the nighttime and also during solar minimum. Furthermore, Liu et al. [2017] indicated that gravity wave activities are stronger at low solar flux levels, which agrees well with that of postmidnight EPIs. These points could possibly explain the anti-correlation between the postmidnight EPIs and F10.7, though a more quantitative calculation is still needed to confirm whether these effects are significant enough. As for the geomagnetic activity dependence, the occurrence rate is collectively influenced by the existence and interaction of prompt penetration electric field, disturbance wind dynamo electric field, and shielding electric field. EPIs 
can be enhanced or suppressed for individual storm cases over different local time sectors, but a net effect shown by Figure 10d is that the occurrence rates are enhanced during high geomagnetic activity period, although the error bars are considerably increased for higher Kp intervals. The geomagnetic activity can impact the EPIs immediately in the case of penetrating electric fields or with a specific time delay in the case of disturbance dynamo. Typically, the largest Kp occurs during the main phase of a storm and the disturbance dynamo has not fully developed yet, so EPIs tend to have a higher occurrence rate. During moderate Kp, such as $4-6$, this is usually a mixture of main and recovery phases, so the electrodynamics are not very clear. Thus, the role of geomagnetic activity in influencing EPIs occurrence rate distribution is still an open question and needs to use numerical models to make a further study in the future.

\section{Conclusion}

In this paper, we present a statistical study of the EPI occurrence rates in the ionospheric F layer by using six years in situ plasma density measurements from the Swarm constellation. The occurrence patterns in terms of longitude, season, local time, latitude, solar activity, and geomagnetic activity levels are analyzed, respectively. The major controlling factors of the spatial-temporal distribution of the postsunset and postmidnight EPIs are also discussed. The main findings and results are summarized as follows:

1. The statistical results from the Swarm and C/NOFS collectively support the feature that postsunset and postmidnight EPI occurrence rates have opposite dependencies on solar activity. The former is positively correlated with the F10.7 index, while the latter is negatively correlated with it. 
2. The postsunset and postmidnight EPIs have asymmetric occurrence distribution. The postsunset EPIs have more significant occurrence rates during the December solstice and equinoxes with a clear longitudinal preference for the Atlantic-American sector. On the other hand, the postmidnight EPIs are more prominent than the postsunset ones during the June solstice with the strongest occurrence peak occurring over the African sector, while the Pacific sector exhibits a considerable postmidnight occurrence enhancement during the December solstice. The occurrence rate around equinoxes within this local time sector is substantially reduced. The main controlling factors for the distribution of postsunset EPIs are the magnetic declination effect, equatorial vertical $\mathrm{E} \times \mathrm{B}$ drift, and thermospheric zonal wind. For the postmidnight EPIs, the main controlling factors are likely to be atmospheric gravity waves and equatorward thermospheric wind associated with midnight temperature maximum.

3. The latitudinal distribution of EPIs exhibits a double-peak structure, with the maximum occurrence rates located around $\pm 5^{\circ}$ magnetic latitude. The northern hemisphere peak is slightly higher than the southern hemisphere peak during the June solstice and equinoxes, while the situation is reversed during the June solstice. This hemispheric asymmetry might be attributed to the effects of trans-equatorial thermospheric wind.

4. Most of the EPIs are constrained within $30^{\circ}$ away from the magnetic equator, and their spatial distribution have a noticeable longitudinal preference. The density irregularity is more frequently detected over the South American sector in the December solstice with the occurrence rate ranging from 40\%-80\%. The longitudinal preference of EPIs extends to the Atlantic and African sectors in the March/September equinoxes, while the occurrence rate over these regions reduces to $20 \%-50 \%$. As for the June solstice, the dis- 


\section{References}

tribution is relatively even with broader longitude coverage, and the peak of occurrence rate shifts to the African sector.

5. The local time distribution of EPIs also exhibits asymmetric patterns over different season/longitudes. During the December solstice and equinoxes, the occurrence rate has peak value in the evening sector around 20-21 LT and becomes much lower after midnight except for the Pacific sector. During the June solstice, the EPI occurrence rate often slowly increases after sunset and reaches a peak value after midnight around 03-04 LT.

6. The general level of EPI occurrence rate increases with respect to the increasing geomagnetic activity level, although the corresponding error bars also increases.

Acknowledgments. This work is sponsored by the Strategic Priority Research Program of Chinese Academy of Sciences (XDA17010302), National Key R\&D Program of China (2016YFB0501503), National Science Foundation of China (41674183, 41974184), Youth Innovation Promotion Association of Chinese Academy of Sciences, and Shenzhen Technology Project JCJ20160817172025986. We greatly acknowledge ESA for SWARM data (http://earth.esa.int/swarm). The F10.7 data is acquired from NASA/GSFCs Space Physics Data Facilitys OMNIWeb service (https://cdaweb.gsfc.nasa.gov/). Kp indices are downloaded from Kyoto world data center for Geomagnetism (http://wdc.kugi.kyotou.ac.jp/). The C/NOFS in situ ion density data is available from NASA/GSFCs Space Physics Data Facilitys OMNIWeb service (https://cdaweb.sci.gsfc.nasa.gov/).

Aa, E., W. Huang, S. Liu, A. Ridley, S. Zou, L. Shi, Y. Chen, H. Shen, T. Yuan, J. Li, and T. Wang (2018), Midlatitude Plasma Bubbles Over China and Adjacent 
Areas During a Magnetic Storm on 8 September 2017, Space Weather, 16, 321-331, doi:10.1002/2017SW001776.

Aa, E., S. Zou, A. J. Ridley, S.-R. Zhang, A. J. Coster, P. J. Erickson, S. Liu, and J. Ren (2019), Merging of storm-time midlatitude traveling ionospheric disturbances and equatorial plasma bubbles, Space Weather, 17, 1-16, doi:10.1029/2018SW002101.

Aa, E., S. Zou, R. Eastes, D. K. Karan, S.-R. Zhang, P. J. Erickson, and A. J. Coster (2020), Coordinated ground-based and space-based observations of equatorial plasma bubbles, Journal of Geophysical Research: Space Physics, 125(1), e2019JA027,569, doi: 10.1029/2019JA027569.

Abdu, M. A. (2001), Outstanding problems in the equatorial ionosphere-thermosphere electrodynamics relevant to spread F, Journal of Atmospheric and Solar-Terrestrial Physics, 63(9), 869-884, doi:10.1016/S1364-6826(00)00201-7.

Abdu, M. A. (2019), Day-to-day and short-term variabilities in the equatorial plasma bubble/spread F irregularity seeding and development, Progress in Earth and Planetary Science, 6, 11, doi:10.1186/s40645-019-0258-1.

Abdu, M. A., I. S. Batista, H. Takahashi, J. MacDougall, J. H. Sobral, A. F. Medeiros, and N. B. Trivedi (2003), Magnetospheric disturbance induced equatorial plasma bubble development and dynamics: A case study in Brazilian sector, J. Geophys. Res., 108, 1449, doi:10.1029/2002JA009721.

Abdu, M. A., I. S. Batista, A. J. Carrasco, and C. Brum (2005), South Atlantic magnetic anomaly ionization: A review and a new focus on electrodynamic effects in the equatorial ionosphere, Journal of Atmospheric and Solar-Terrestrial Physics, 67(17), 1643-1657, doi:10.1016/j.jastp.2005.01.014. 
491

Aveiro, H. C., D. L. Hysell, R. G. Caton, K. M. Groves, J. Klenzing, R. F. Pfaff, R. Stoneback, and R. A. Heelis (2012), Three-dimensional numerical simulations of equatorial spread F: Results and observations in the Pacific sector, J. Geophys. Res., 117, A03325, doi:10.1029/2011JA017077.

Basu, S., and S. Basu (1985), Equatorial scintillations: advances since ISEA-6, Journal of Atmospheric and Terrestrial Physics, 47(8), 753-768, doi:10.1016/0021-9169(85)900522.

Basu, S., S. Basu, K. M. Groves, H.-C. Yeh, S.-Y. Su, F. J. Rich, P. J. Sultan, and M. J. Keskinen (2001), Response of the equatorial ionosphere in the South Atlantic Region to the Great Magnetic Storm of July 15, 2000, Geophys. Res. Lett., 28, 3577-3580, doi:10.1029/2001GL013259.

Bhattacharyya, A., S. Basu, K. M. Groves, C. E. Valladares, and R. Sheehan (2001), Dynamics of equatorial F region irregularities from spaced receiver scintillation observations, Geophys. Res. Lett., 28, 119-122, doi:10.1029/2000GL012288.

Blanch, E., D. Altadill, J. M. Juan, A. Camps, J. Barbosa, G. González-Casado, J. Riba, J. Sanz, G. Vazquez, and R. Orús-Pérez (2018), Improved characterization and modeling of equatorial plasma depletions, Journal of Space Weather and Space Climate, 8, A38, doi:10.1051/swsc/2018026.

Burke, W., C. Huang, L. Gentile, and L. Bauer (2004a), Seasonal-longitudinal variability of equatorial plasma bubbles, Annales Geophysicae, 22, 3089-3098, doi:10.5194/angeo22-3089-2004.

Burke, W. J., L. C. Gentile, C. Y. Huang, C. E. Valladares, and S. Y. Su (2004b), Longitudinal variability of equatorial plasma bubbles observed by DMSP and ROCSAT- 
1, J. Geophys. Res., $109(\mathrm{~A} 18)$, A12301, doi:10.1029/2004JA010583.

Carter, B. A., K. Zhang, R. Norman, V. V. Kumar, and S. Kumar (2013), On the occurrence of equatorial F-region irregularities during solar minimum using radio occultation measurements, J. Geophys. Res. Space Physics, 118, 892-904, doi:10.1002/jgra.50089.

Carter, B. A., E. Yizengaw, R. Pradipta, J. M. Retterer, K. Groves, C. Valladares, R. Caton, C. Bridgwood, R. Norman, and K. Zhang (2016), Global equatorial plasma bubble occurrence during the 2015 St. Patrick's Day storm, J. Geophys. Res. Space Physics, 121, 894-905, doi:10.1002/2015JA022194.

Cherniak, I., and I. Zakharenkova (2016), First observations of super plasma bubbles in Europe, Geophys. Res. Lett., 43, 11, doi:10.1002/2016GL071421.

Cherniak, I., I. Zakharenkova, and S. Sokolovsky (2019), Multi-Instrumental Observation of Storm-Induced Ionospheric Plasma Bubbles at Equatorial and Middle Latitudes, Journal of Geophysical Research: Space Physics, 124(3), 1491-1508, doi: 10.1029/2018JA026309.

Comberiate, J., and L. J. Paxton (2010), Coordinated UV imaging of equatorial plasma bubbles using TIMED/GUVI and DMSP/SSUSI, Space Weather, 8, S10002, doi: 10.1029/2009SW000546.

Dao, E., M. C. Kelley, P. Roddy, J. Retterer, J. O. Ballenthin, O. de La Beaujardiere, and Y.-J. Su (2011), Longitudinal and seasonal dependence of nighttime equatorial plasma density irregularities during solar minimum detected on the C/NOFS satellite, Geophys. Res. Lett., 38, L10104, doi:10.1029/2011GL047046.

Eccles, J. V., J. P. St. Maurice, and R. W. Schunk (2015), Mechanisms underlying the prereversal enhancement of the vertical plasma drift in the low-latitude ionosphere, Journal 
of Geophysical Research Space Physics, 120, 4950-4970, doi:10.1002/2014JA020664.

Fejer, B. G., L. Scherliess, and E. R. de Paula (1999), Effects of the vertical plasma drift velocity on the generation and evolution of equatorial spread F, J. Geophys. Res., 104, 19,859-19,870, doi:10.1029/1999JA900271.

Gentile, L. C., W. J. Burke, and F. J. Rich (2006), A global climatology for equatorial plasma bubbles in the topside ionosphere, Annales Geophysicae, 24(1), 163-172, doi: 10.5194/angeo-24-163-2006.

Huang, C.-S. (2016), Plasma drifts and polarization electric fields associated with TID-like disturbances in the low-latitude ionosphere: C/NOFS observations, Journal of Geophysical Research: Space Physics, 121(2), 1802-1812, doi:10.1002/2015JA022201.

Huang, C.-S., J. C. Foster, and Y. Sahai (2007), Significant depletions of the ionospheric plasma density at middle latitudes: A possible signature of equatorial spread $\mathrm{F}$ bubbles near the plasmapause, J. Geophys. Res., 112, A05315, doi:10.1029/2007JA012307.

Huang, C.-S., F. J. Rich, and W. J. Burke (2010), Storm time electric fields in the equatorial ionosphere observed near the dusk meridian, J. Geophys. Res., 115, A08313, doi:10.1029/2009JA015150.

Huang, C.-S., O. de La Beaujardiere, P. A. Roddy, D. E. Hunton, J. O. Ballenthin, and M. R. Hairston (2012), Generation and characteristics of equatorial plasma bubbles detected by the C/NOFS satellite near the sunset terminator, J. Geophys. Res., 117(A16), A11313, doi:10.1029/2012JA018163.

Huang, C.-S., O. La Beaujardiere, P. A. Roddy, D. E. Hunton, J. Y. Liu, and S. P. Chen (2014), Occurrence probability and amplitude of equatorial ionospheric irregularities associated with plasma bubbles during low and moderate solar activities (2008-2012), 
J. Geophys. Res. Space Physics, 119, 1186-1199, doi:10.1002/2013JA019212.

Huang, C. Y., W. J. Burke, J. S. Machuzak, L. C. Gentile, and P. J. Sultan (2001), DMSP observations of equatorial plasma bubbles in the topside ionosphere near solar maximum, J. Geophys. Res., 106, 8131-8142, doi:10.1029/2000JA000319.

Huang, C. Y., W. J. Burke, J. S. Machuzak, L. C. Gentile, and P. J. Sultan (2002), Equatorial plasma bubbles observed by DMSP satellites during a full solar cycle: Toward a global climatology, J. Geophys. Res., 107, 1434, doi:10.1029/2002JA009452.

Huba, J. D., and G. Joyce (2007), Equatorial spread F modeling: Multiple bifurcated structures, secondary instabilities, large density 'bite-outs,' and supersonic flows, Geophys. Res. Lett., 34, L07105, doi:10.1029/2006GL028519.

Huba, J. D., and J. Krall (2013), Impact of meridional winds on equatorial spread F: Revisited, Geophys. Res. Lett., 40(7), 1268-1272, doi:10.1002/grl.50292.

Huba, J. D., G. Joyce, and J. Krall (2008), Three-dimensional equatorial spread F modeling, Geophys. Res. Lett., 35, L10102, doi:10.1029/2008GL033509.

Jin, H., S. Zou, G. Chen, C. Yan, S. Zhang, and G. Yang (2018), Formation and Evolution of Low-Latitude F Region Field-Aligned Irregularities During the 7-8 September 2017 Storm: Hainan Coherent Scatter Phased Array Radar and Digisonde Observations, Space Weather, 16, 648-659, doi:10.1029/2018SW001865.

Katamzi-Joseph, Z. T., J. B. Habarulema, and M. Hernández-Pajares (2017), Midlatitude postsunset plasma bubbles observed over europe during intense storms in april 2000 and 2001, Space Weather, 15(9), 1177-1190, doi:10.1002/2017SW001674.

Kelley, M. C., G. Haerendel, H. Kappler, A. Valenzuela, B. B. Balsley, D. A. Carter, W. L. Ecklund, C. W. Carlson, B. Haeusler, and R. Torbert (1976), Evidence for a 
Rayleigh-Taylor type instability and upwelling of depleted density regions during equatorial spread F, Geophys. Res. Lett., 3, 448-450, doi:10.1029/GL003i008p00448.

Kelley, M. C., J. J. Makela, L. J. Paxton, F. Kamalabadi, J. M. Comberiate, and H. Kil (2003), The first coordinated ground- and space-based optical observations of equatorial plasma bubbles, Geophys. Res. Lett., 30, 1766, doi:10.1029/2003GL017301.

Kil, H., and R. A. Heelis (1998), Global distribution of density irregularities in the equatorial ionosphere, J. Geophys. Res., 103, 407-418, doi:10.1029/97JA02698.

Kil, H., R. A. Heelis, L. J. Paxton, and S.-J. Oh (2009a), Formation of a plasma depletion shell in the equatorial ionosphere, J. Geophys. Res., 114(A13), A11302, doi: 10.1029/2009JA014369.

Kil, H., L. J. Paxton, and S.-J. Oh (2009b), Global bubble distribution seen from ROCSAT-1 and its association with the evening prereversal enhancement, J. Geophys. Res., 114, A06307, doi:10.1029/2008JA013672.

Krall, J., J. D. Huba, S. L. Ossakow, G. Joyce, J. J. Makela, E. S. Miller, and M. C. Kelley (2011), Modeling of equatorial plasma bubbles triggered by non-equatorial traveling ionospheric disturbances, Geophys. Res. Lett., 38, L08103, doi:10.1029/2011GL046890.

Kudeki, E., A. Akgiray, M. Milla, J. L. Chau, and D. L. Hysell (2007), Equatorial spread-F initiation: Post-sunset vortex, thermospheric winds, gravity waves, Journal of Atmospheric and Solar-Terrestrial Physics, 69(17-18), 2416-2427, doi: 10.1016/j.jastp.2007.04.012.

Li, G., B. Ning, M. A. Abdu, X. Yue, L. Liu, W. Wan, and L. Hu (2011), On the occurrence of postmidnight equatorial $\mathrm{F}$ region irregularities during the June solstice, Journal of Geophysical Research: Space Physics, 116(A4), A04318, doi:10.1029/2010JA016056. 
Li, G., B. Ning, M. A. Abdu, Y. Otsuka, T. Yokoyama, M. Yamamoto, and L. Liu (2013), Longitudinal characteristics of spread F backscatter plumes observed with the EAR and Sanya VHF radar in Southeast Asia, J. Geophys. Res., 118, 6544-6557, doi: $10.1002 /$ jgra. 50581.

Li, G., B. Ning, C. Wang, M. A. Abdu, Y. Otsuka, M. Yamamoto, J. Wu, and J. Chen (2018), Storm-enhanced development of post-sunset equatorial plasma bubbles around the meridian 120E/60W on 7-8 September 2017, J. Geophys. Res. Space Physics, 123, 1-16, doi:10.1029/2018JA025871.

Liu, H., E. Doornbos, and J. Nakashima (2016), Thermospheric wind observed by goce: Wind jets and seasonal variations, Journal of Geophysical Research: Space Physics, 121 (7), 6901-6913, doi:10.1002/2016JA022938.

Liu, H., N. Pedatella, and K. Hocke (2017), Medium-scale gravity wave activity in the bottomside F region in tropical regions, Geophysical Research Letters, 44(14), 70997105, doi:10.1002/2017GL073855.

Lühr, H., C. Xiong, J. Park, and J. Rauberg (2014), Systematic study of intermediatescale structures of equatorial plasma irregularities in the ionosphere based on CHAMP observations, Frontiers in Physics, 2, 15, doi:10.3389/fphy.2014.00015.

Lühr, H., G. Kervalishvili, J. Rauberg, and C. Stolle (2016), Zonal currents in the F region deduced from Swarm constellation measurements, Journal of Geophysical Research Space Physics, 121, 638-648, doi:10.1002/2015JA022051.

Ma, G., and T. Maruyama (2006), A super bubble detected by dense GPS network at east Asian longitudes, Geophys. Res. Lett., 33, L21103, doi:10.1029/2006GL027512.

Makela, J. J., and M. C. Kelley (2003), Field-aligned 777.4-nm composite airglow images of 
equatorial plasma depletions, Geophys. Res. Lett., 30, 1442, doi:10.1029/2003GL017106.

Makela, J. J., and E. S. Miller (2011), Influences on the Development of Equatorial Plasma Bubbles: Insights from a Long-Term Optical Dataset, pp. 239-249, Springer Netherlands, Dordrecht.

Martinis, C., J. Baumgardner, M. Mendillo, J. Wroten, A. Coster, and L. Paxton (2015), The night when the auroral and equatorial ionospheres converged, J. Geophys. Res. Space Physics, 120, 8085-8095, doi:10.1002/2015JA021555.

Maruyama, T. (1988), A diagnostic model for equatorial spread F. 1. Model description and application to electric field and neutral wind effects, J. Geophys. Res., 93(A12), 14,611-14,622, doi:10.1029/JA093iA12p14611.

Nicolls, M. J., M. C. Kelley, M. N. Vlasov, Y. Sahai, J. L. Chau, D. L. Hysell, P. R. Fagundes, F. Becker-Guedes, and W. L. C. Lima (2006), Observations and modeling of post-midnight uplifts near the magnetic equator, Annales Geophysicae, 24, 1317-1331, doi:10.5194/angeo-24-1317-2006.

Nishioka, M., A. Saito, and T. Tsugawa (2008), Occurrence characteristics of plasma bubble derived from global ground-based GPS receiver networks, J. Geophys. Res., 113, A05301, doi:10.1029/2007JA012605.

Nishioka, M., Y. Otsuka, K. Shiokawa, T. Tsugawa, n. Effendy, P. Supnithi, T. Nagatsuma, and K. T. Murata (2012), On post-midnight field-aligned irregularities observed with a 30.8- $\mathrm{MHz}$ radar at a low latitude: Comparison with F-layer altitude near the geomagnetic equator, Journal of Geophysical Research, 117, A08337, doi: 10.1029/2012JA017692.

Otsuka, Y. (2018), Review of the generation mechanisms of post-midnight irregularities 
652

in the equatorial and low-latitude ionosphere, Progress in Earth and Planetary Science, 5, 57, doi:10.1186/s40645-018-0212-7.

Ott, E. (1978), Theory of Rayleigh-Taylor bubbles in the equatorial ionosphere, J. Geophys. Res., 83, 2066-2070, doi:10.1029/JA083iA05p02066.

Pudovkin, M. I. (1974), Electric Fields and Currents in the Ionosphere, Space Science Reviews, 16(5-6), 727-770, doi:10.1007/BF00182599.

Retterer, J. M., and L. C. Gentile (2009), Modeling the climatology of equatorial plasma bubbles observed by DMSP, Radio Science, 44(A5), RS0A31, doi: 10.1029/2008RS004057.

Retterer, J. M., and P. Roddy (2014), Faith in a seed: on the origins of equatorial plasma bubbles, Ann. Geophys., 32, 485-498, doi:10.5194/angeo-32-485-2014.

Rodríguez-Zuluaga, J., C. Stolle, and J. Park (2017), On the direction of the Poynting flux associated with equatorial plasma depletions as derived from Swarm, Geophysical Research Letters, 44(12), 5884-5891, doi:10.1002/2017GL073385.

Smith, J., and R. A. Heelis (2017), Equatorial plasma bubbles: Variations of occurrence and spatial scale in local time, longitude, season, and solar activity, J. Geophys. Res. Space Physics, 122, 5743-5755, doi:10.1002/2017JA024128.

Stolle, C., H. Lühr, M. Rother, and G. Balasis (2006), Magnetic signatures of equatorial spread F as observed by the CHAMP satellite, J. Geophys. Res., 111, A02304, doi: 10.1029/2005JA011184.

Su, S.-Y., C. H. Liu, H. H. Ho, and C. K. Chao (2006), Distribution characteristics of topside ionospheric density irregularities: Equatorial versus midlatitude regions, $J$. Geophys. Res., 111, A06305, doi:10.1029/2005JA011330. 
Su, S.-Y., C. K. Chao, and C. H. Liu (2008), On monthly/seasonal/longitudinal variations of equatorial irregularity occurrences and their relationship with the postsunset vertical drift velocities, J. Geophys. Res., 113, A05307, doi:10.1029/2007JA012809.

Sultan, P. J. (1996), Linear theory and modeling of the Rayleigh-Taylor instability leading to the occurrence of equatorial spread F, J. Geophys. Res., 101, 26,875-26,892, doi: 10.1029/96JA00682.

Tsunoda, R. T. (1980), Magnetic-field-aligned characteristics of plasma bubbles in the nighttime equatorial ionosphere, J. Atmos. Terr. Phys., 42, 743-752, doi:10.1016/00219169(80)90057-4.

Tsunoda, R. T. (1985), Control of the seasonal and longitudinal occurrence of equatorial scintillations by the longitudinal gradient in integrated E region Pedersen conductivity, J. Geophys. Res., 90, 447-456, doi:10.1029/JA090iA01p00447.

Tsunoda, R. T., R. C. Livingston, J. P. McClure, and W. B. Hanson (1982), Equatorial plasma bubbles - Vertically elongated wedges from the bottomside F layer, J. Geophys. Res., 87, 9171-9180, doi:10.1029/JA087iA11p09171.

Wan, X., C. Xiong, J. Rodriguez-Zuluaga, G. N. Kervalishvili, C. Stolle, and H. Wang (2018), Climatology of the Occurrence Rate and Amplitudes of Local Time Distinguished Equatorial Plasma Depletions Observed by Swarm Satellite, J. Geophys. Res. Space Physics, 123, 3014-3026, doi:10.1002/2017JA025072.

Woodman, R. F., and C. La Hoz (1976), Radar observations of F region equatorial irregularities, J. Geophys. Res., 81(31), 5447-5466, doi:10.1029/JA081i031p05447.

Xiong, C., J. Park, H. Lühr, C. Stolle, and S. Y. Ma (2010), Comparing plasma bubble occurrence rates at CHAMP and GRACE altitudes during high and low solar activity, 
Annales Geophysicae, 28, 1647-1658, doi:10.5194/angeo-28-1647-2010.

Xiong, C., H. Lühr, S. Y. Ma, C. Stolle, and B. G. Fejer (2012), Features of highly structured equatorial plasma irregularities deduced from CHAMP observations, Annales Geophysicae, 30, 1259-1269, doi:10.5194/angeo-30-1259-2012.

Xiong, C., C. Stolle, H. Lühr, J. Park, B. G. Fejer, and G. N. Kervalishvili (2016), Scale analysis of equatorial plasma irregularities derived from Swarm constellation, Earth, Planets, and Space, 68, 121, doi:10.1186/s40623-016-0502-5.

Xiong, C., J. Xu, K. Wu, and W. Yuan (2018), Longitudinal thin structure of equatorial plasma depletions coincidently observed by swarm constellation and all-sky imager, $J$. Geophys. Res. Space Physics, 123(2), 1593-1602, doi:10.1002/2017JA025091.

Yizengaw, E., and K. M. Groves (2018), Longitudinal and seasonal variability of equatorial ionospheric irregularities and electrodynamics, Space Weather, 16(8), 946-968, doi: 10.1029/2018SW001980.

Yizengaw, E., J. Retterer, E. E. Pacheco, P. Roddy, K. Groves, R. Caton, and P. Baki (2013), Postmidnight bubbles and scintillations in the quiet-time June solstice, Geophys. Res. Lett., 40, 5592-5597, doi:10.1002/2013GL058307.

Yizengaw, E., M. B. Moldwin, E. Zesta, C. M. Biouele, B. Damtie, A. Mebrahtu, B. Rabiu, C. F. Valladares, and R. Stoneback (2014), The longitudinal variability of equatorial electrojet and vertical drift velocity in the African and American sectors, Annales Geophysicae, 32, 231-238, doi:10.5194/angeo-32-231-2014.

Yokoyama, T., and S. Fukao (2006), Upwelling backscatter plumes in growth phase of equatorial spread F observed with the Equatorial Atmosphere Radar, Geophys. Res. Lett., 33, L08104, doi:10.1029/2006GL025680. 
Yokoyama, T., R. F. Pfaff, P. A. Roddy, M. Yamamoto, and Y. Otsuka (2011), On postmidnight low-latitude ionospheric irregularities during solar minimum: 2. C/NOFS observations and comparisons with the Equatorial Atmosphere Radar, Journal of Geophysical Research Space Physics, 116(A15), A11326, doi:10.1029/2011JA016798.

Yokoyama, T., H. Shinagawa, and H. Jin (2014), Nonlinear growth, bifurcation, and pinching of equatorial plasma bubble simulated by three-dimensional high-resolution bubble model, Journal of Geophysical Research: Space Physics, 119(12), 10,474-10,482, doi:10.1002/2014JA020708.

Yu, T., Y. Miyoshi, C. Xia, X. Zuo, X. Yan, N. Yang, Y. Sun, X. Yue, and T. Mao (2018), Solar Dependence of Equatorial F Region Irregularities Observed by COSMIC Radio Occultations, J. Geophys. Res. Space Physics, 123, 9775-9787, doi:10.1029/2018JA025936.

Zakharenkova, I., E. Astafyeva, and I. Cherniak (2016), GPS and in situ Swarm observations of the equatorial plasma density irregularities in the topside ionosphere, Earth, Planets, and Space, 68, 120, doi:10.1186/s40623-016-0490-5. 

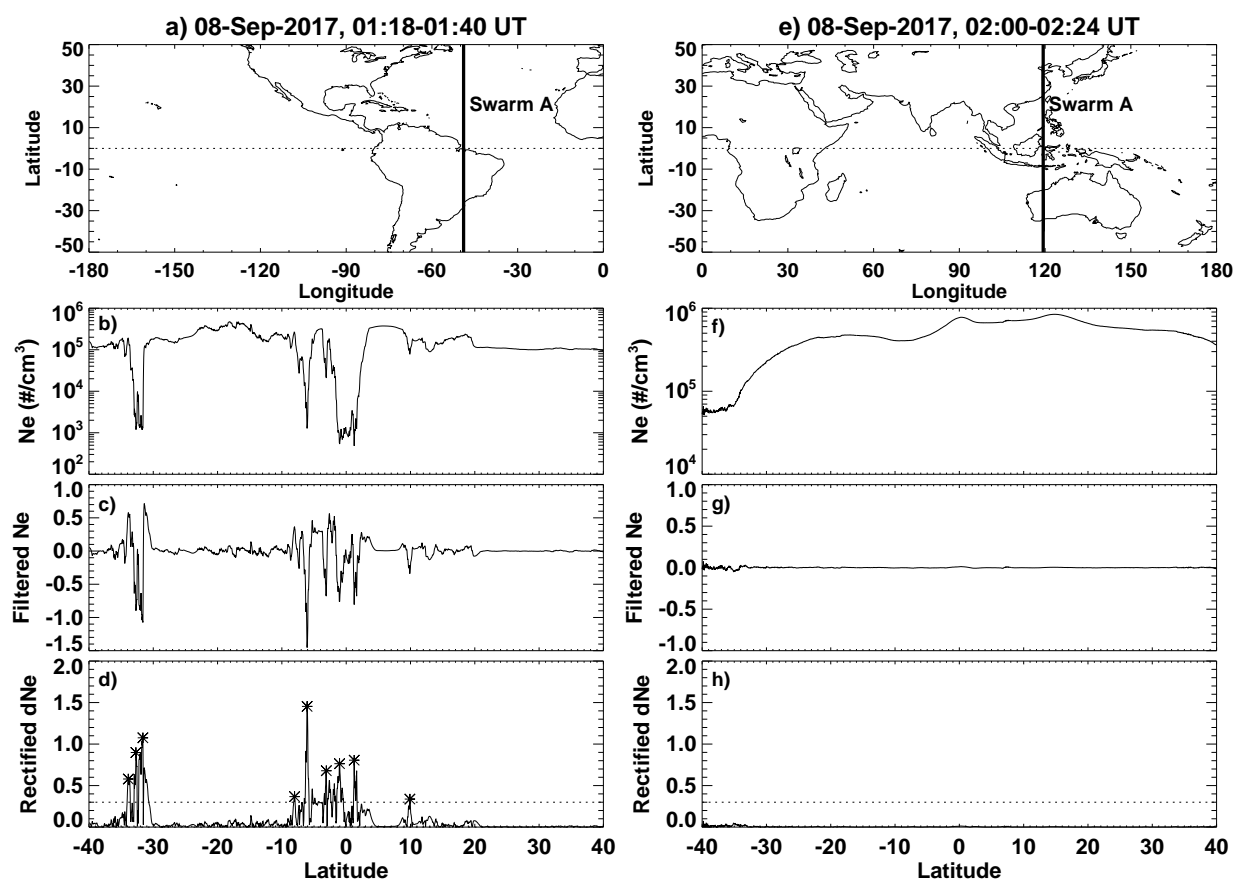

Figure 1. Example of EPIs measured by Swarm A satellite on September 08, 2017. (a) The global map with an orbit of Swarm A being superposed, (b) the corresponding Ne profile as a function of latitude in log scale, (c) high-pass filtered Ne, and (d) rectified residuals. (e)-(h) are the same as (a)-(d), but for another orbit with no EPIs being detected. The detected EPIs are marked with asterisk. EPIs = equatorial plasma irregularities. 

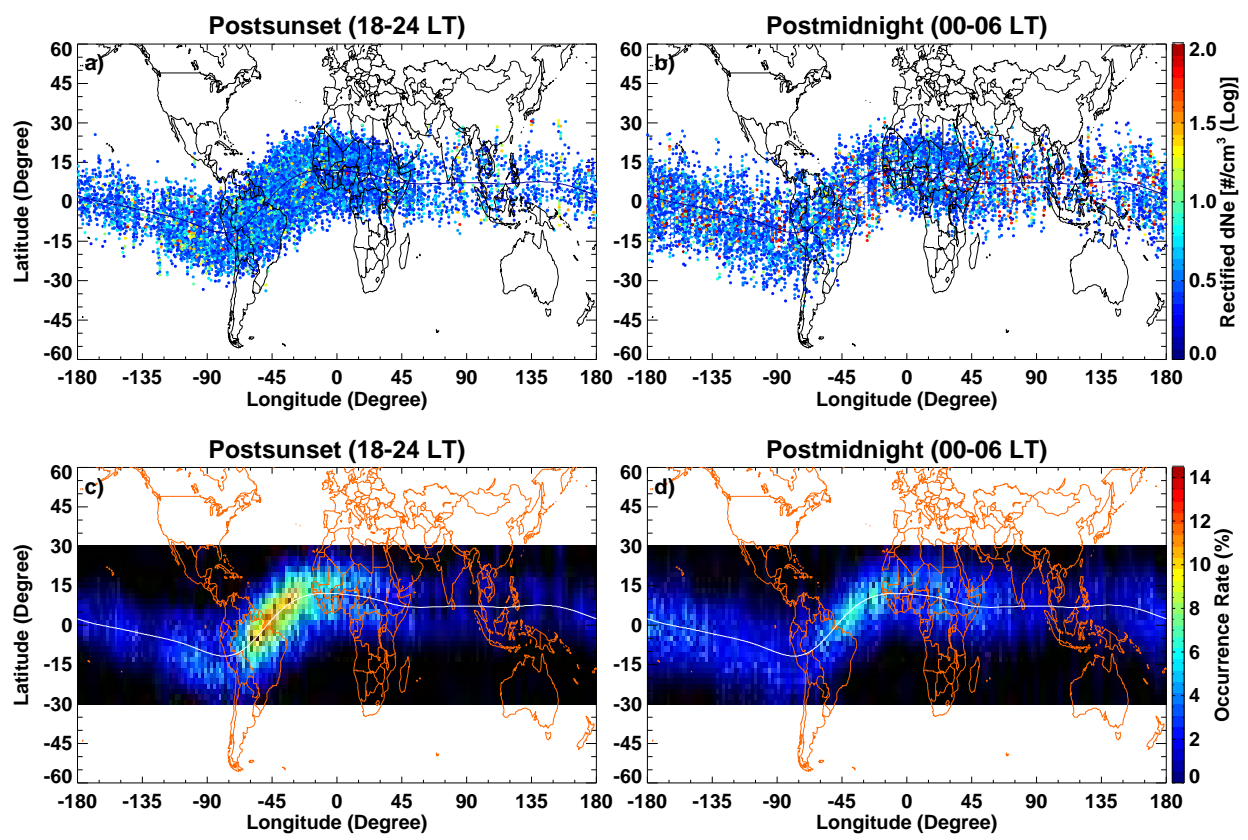

Figure 2. Global distribution of EPIs amplitudes during (a) postsunset and (b) postmidnight period. Global distribution of EPIs occurrence rate during (c) postsunset and (d) postmidnight period. The geomagnetic equator is also plotted. EPIs = equatorial plasma irregularities. 

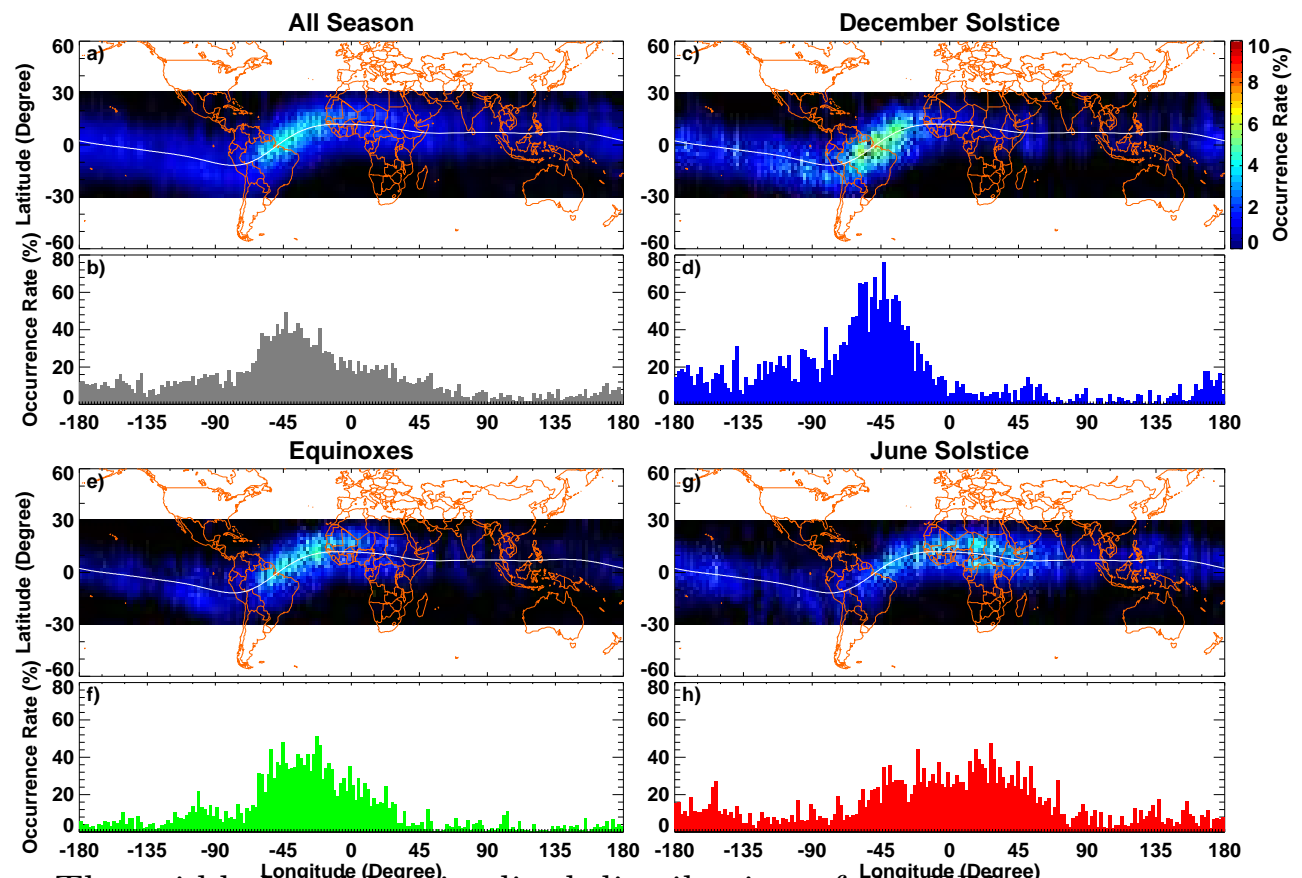

Figure 3. The gridded angitude (Pegree). Tongtudinal distribution of the Engitude(Pegree) occurrence rate for all-season

( $a$ and $b$ ), the December solstice (c and d), the spring/autumn equinoxes (e and $\mathrm{f}$ ), and the June solstice (g and h). The thick white curve represents the geomagnetic equator. EPI = equatorial plasma irregularity. 

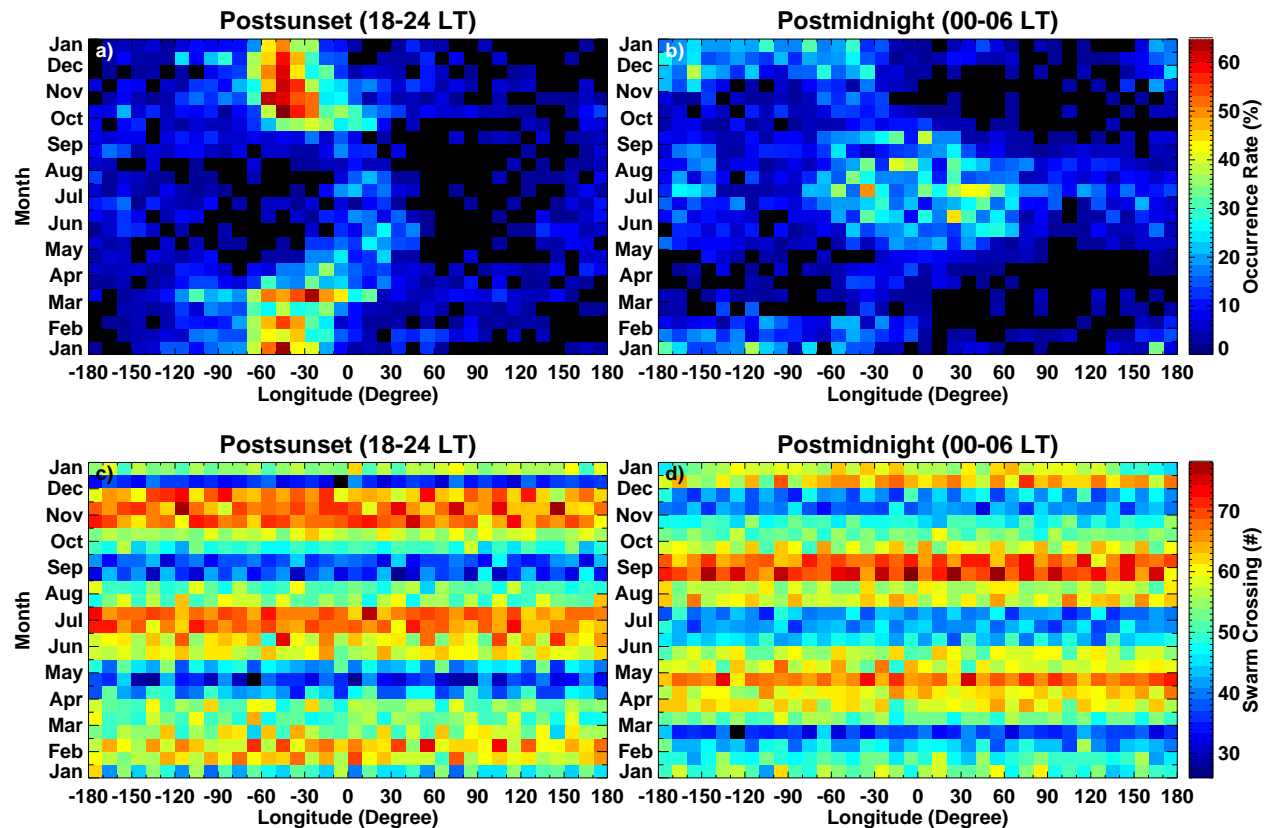

Figure 4. Seasonal-longitudinal distribution of the EPI occurrence rate (top panels) and the Swarm crossing counts (bottom panels) during the postsunset and postmidnight periods, respectively. EPI = equatorial plasma irregularity. 


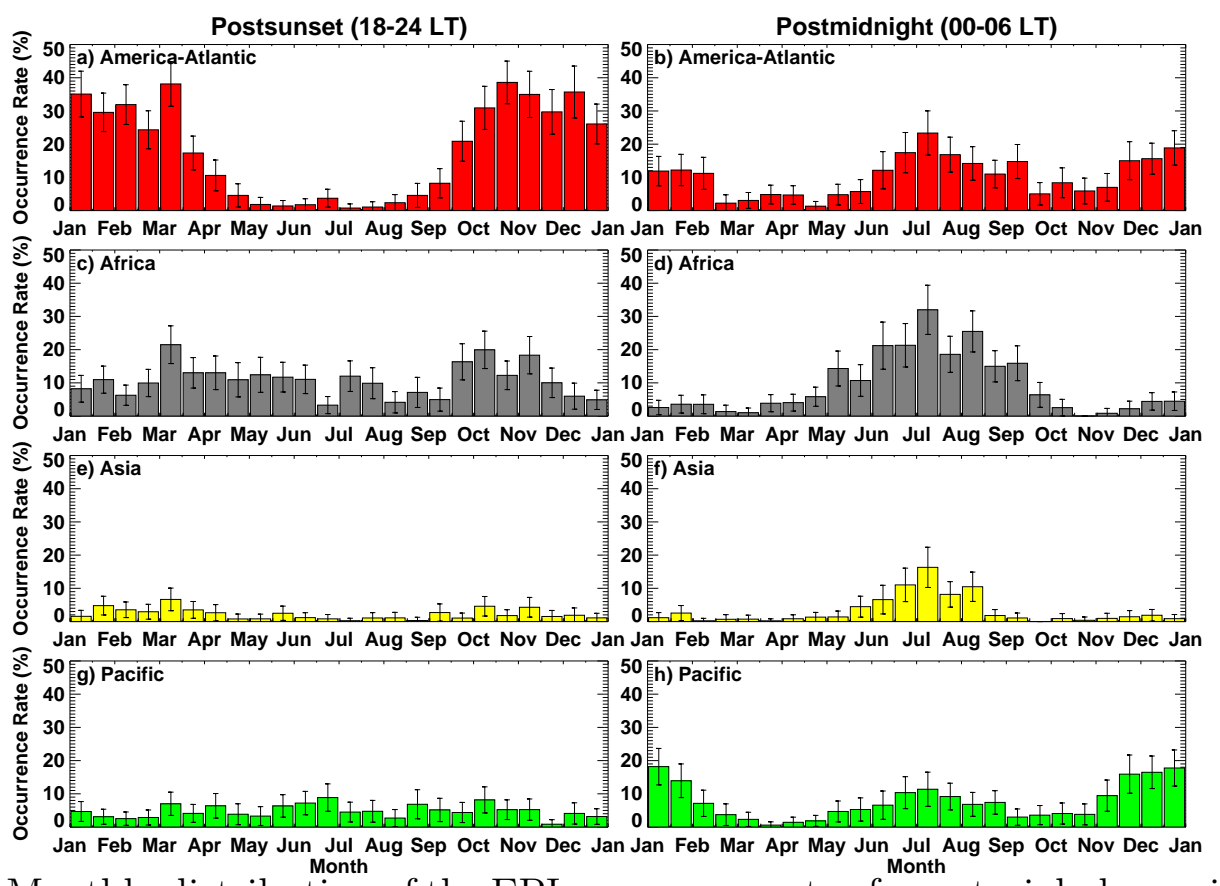

Figure 5. Monthly distribution of the EPI occurrence rate of equatorial plasma irregularities for four different longitudinal sectors during the postsunset and postmidnight periods, respectively. The binsize is half a month. The error bars are also marked. EPI = equatorial plasma irregularity. 

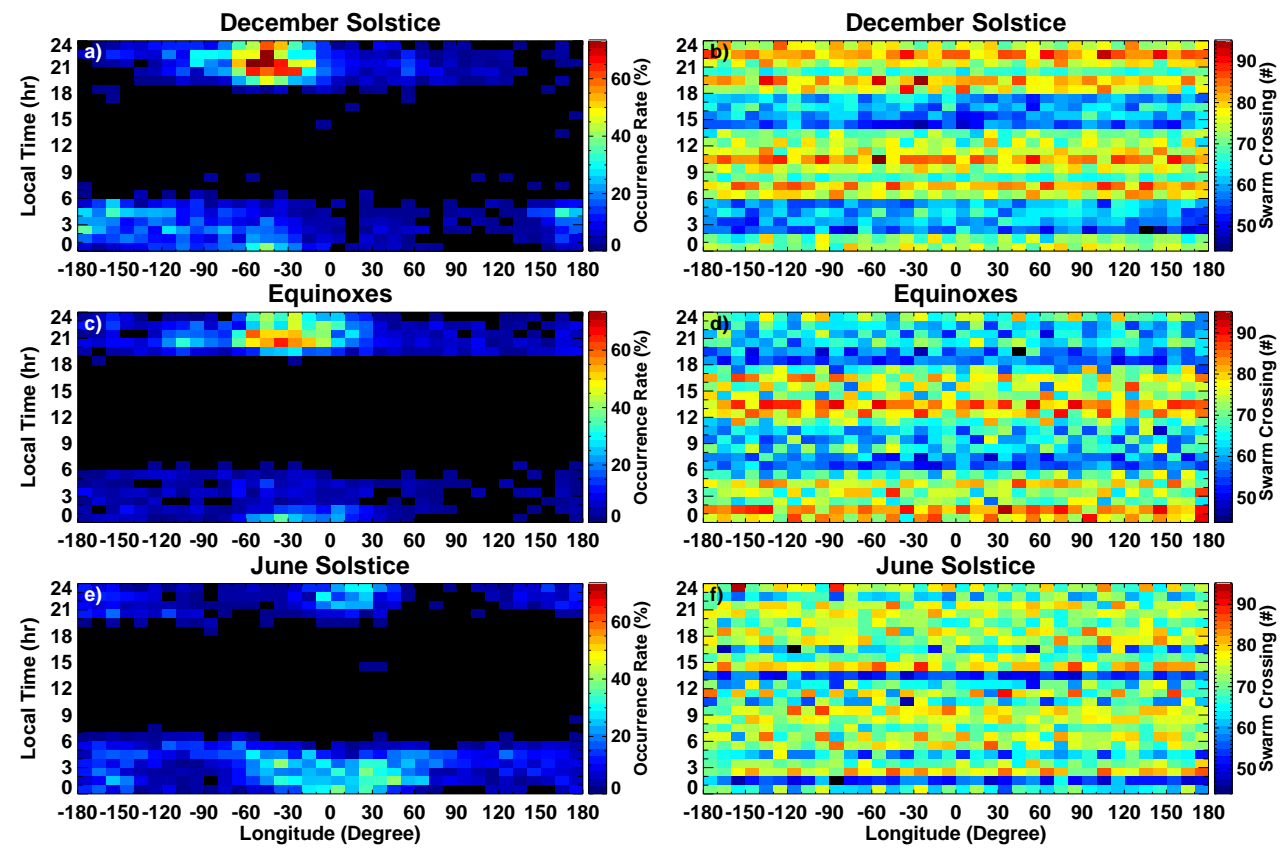

Figure 6. Longitudinal-local time distribution of the EPI occurrence rate(left panels) and the Swarm crossing counts (right panels) during the December solstice, equinoxes, and the June solstices, respectively. EPI = equatorial plasma irregularity. 


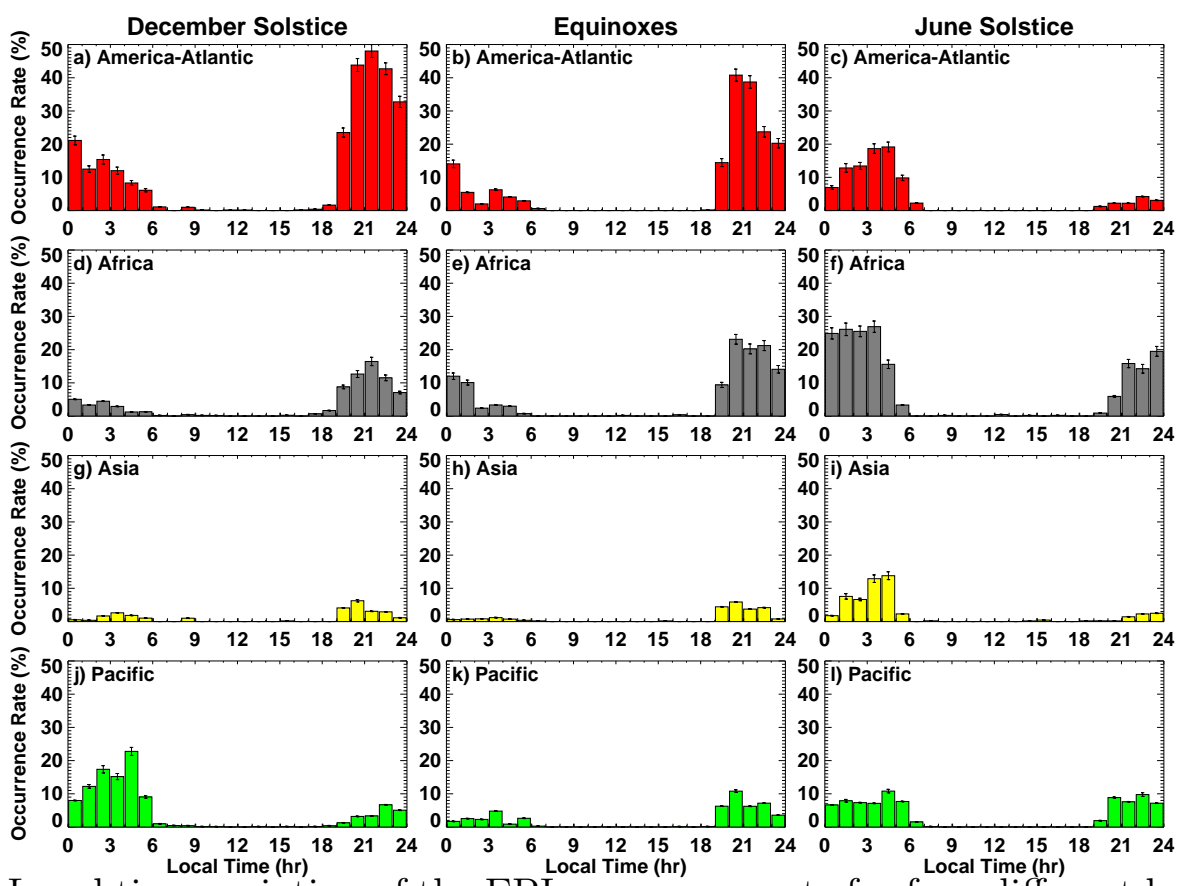

Figure 7. Local time variation of the EPI occurrence rate for four different longitudinal sectors during the December solstice, equinoxes, and the June solstice, respectively. The error bars are also marked. EPI = equatorial plasma irregularity. 

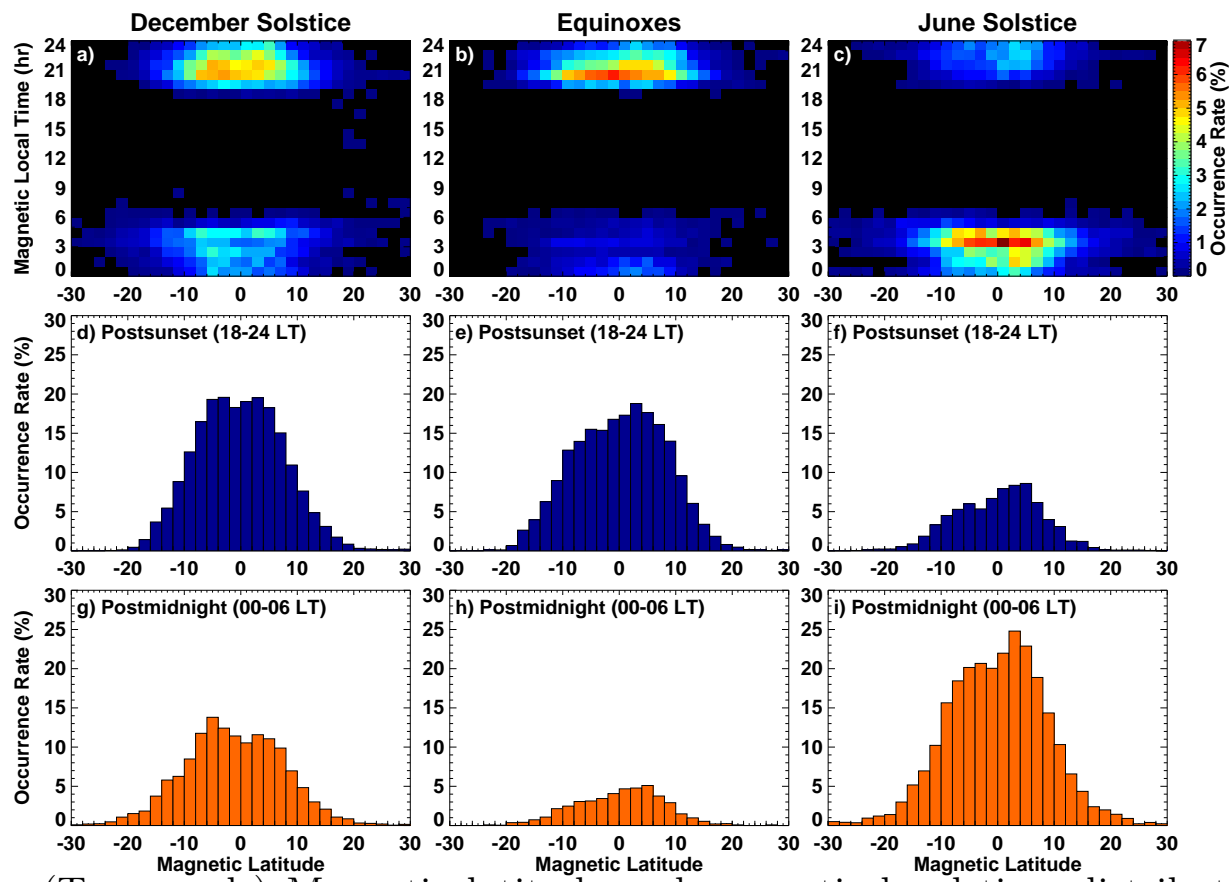

Figure 8. (Top panels) Magnetic latitude and magnetic local time distribution of the EPI occurrence rate during the December solstice, equinoxes, and the June solstice, respectively. (Middle and bottom panels) Latitudinal variation of the EPI occurrence rate during the postsunset and postmidnight periods, respectively. EPI = equatorial plasma irregularity. 


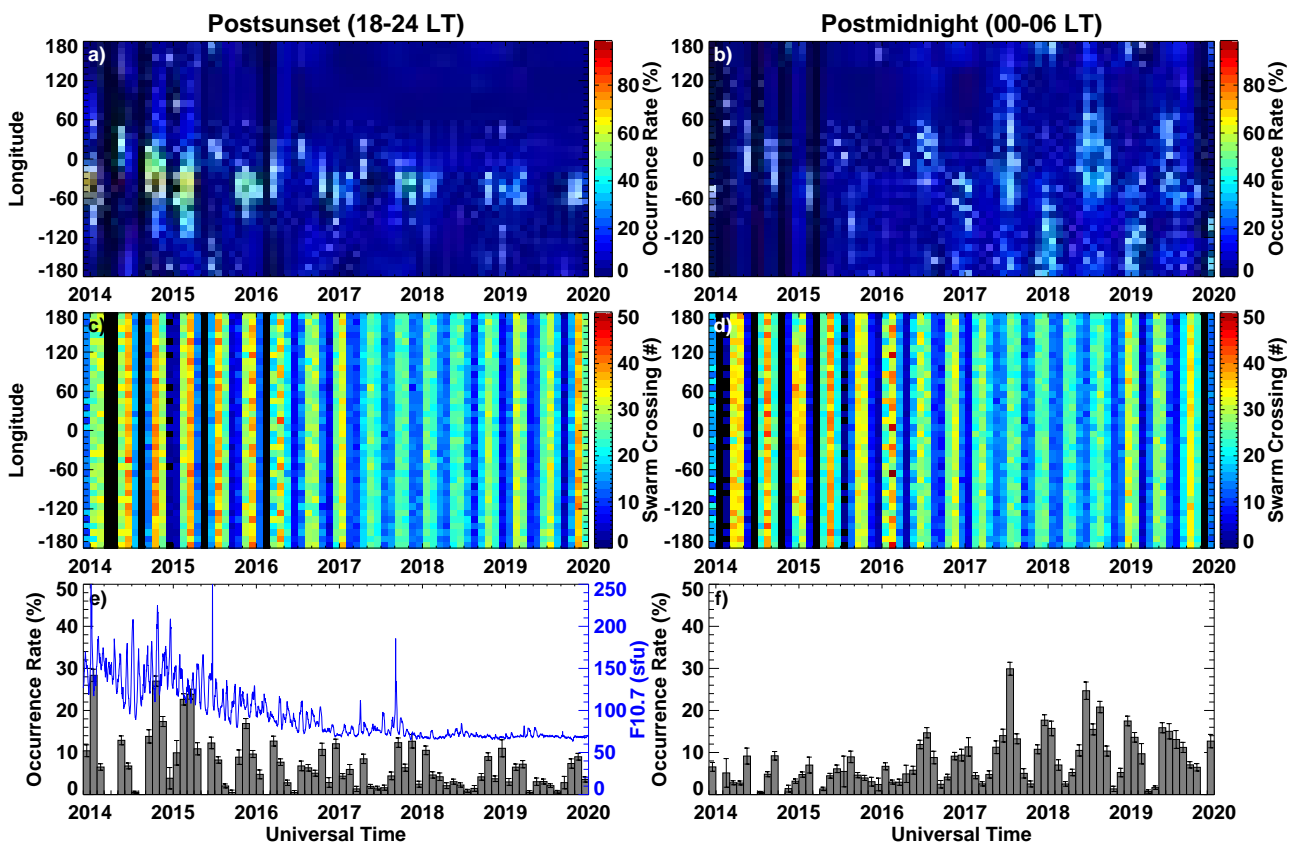

Figure 9. Multi-year longitudinal-monthly distribution of the EPI occurrence rate (top panels), the Swarm crossing counts (middle panels), and the monthly variation of the occurrence rate (bottom panels) during 2013-2019 for the postsunset and postmidnight periods, respectively. The temporal variation of daily F10.7 index is also plotted. EPI = equatorial plasma irregularity. 

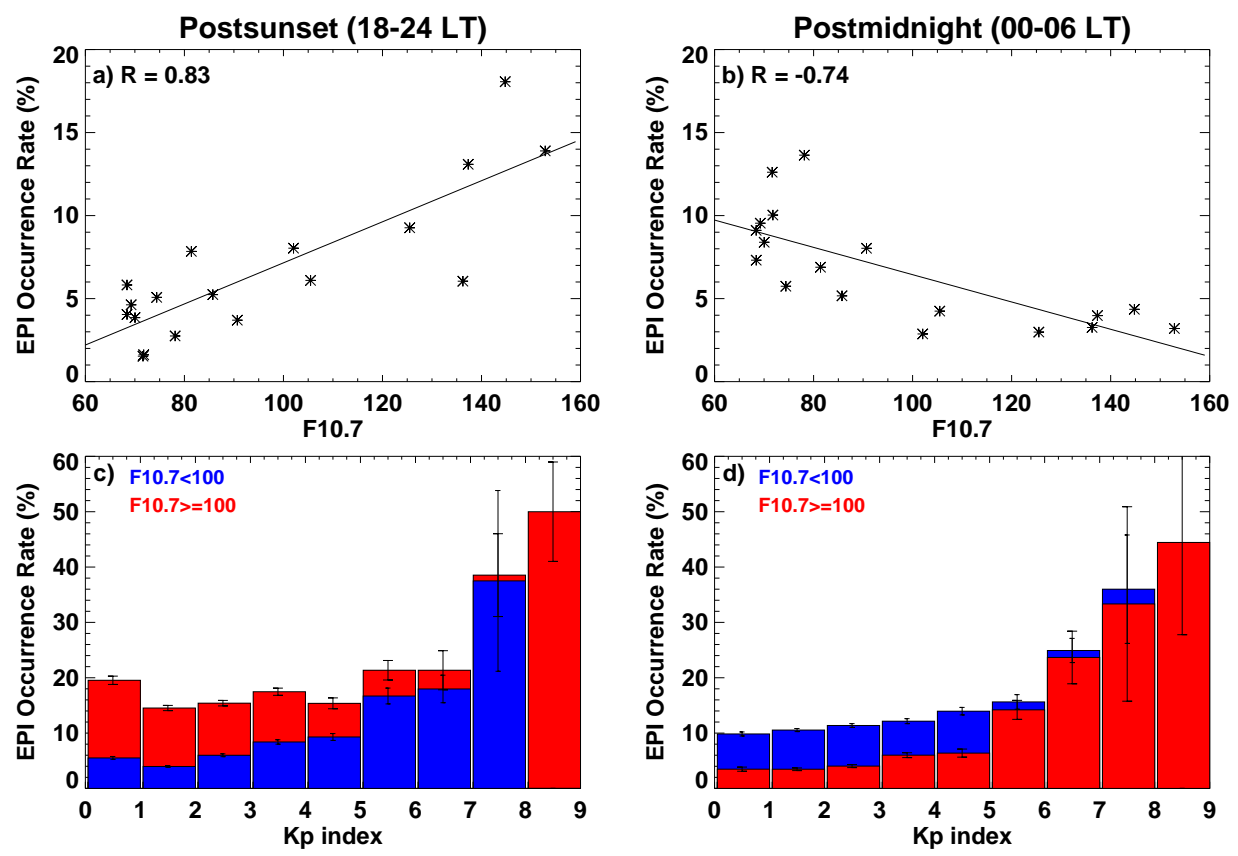

Figure 10. Scatter plots of the four-month average F10.7 index versus the EPI occurrence rate during the (a) postsunset and (b) postmidnight periods, respectively; The EPI occurrence rate as a function of Kp index during the (c) postsunset and (d) postmidnight periods, respectively. The blue and red bars represent low solar activity $(\mathrm{F} 10.7<100)$ and moderate to high solar activity (F10.7 $\geq 100)$ situations, respectively. The bin of $0-1$ includes the data with Kp equal to 0 and 1-, and the bin of 1-2 include the data with Kp equal to 1, 1+, 2-, and so on. EPI = equatorial plasma irregularity. 

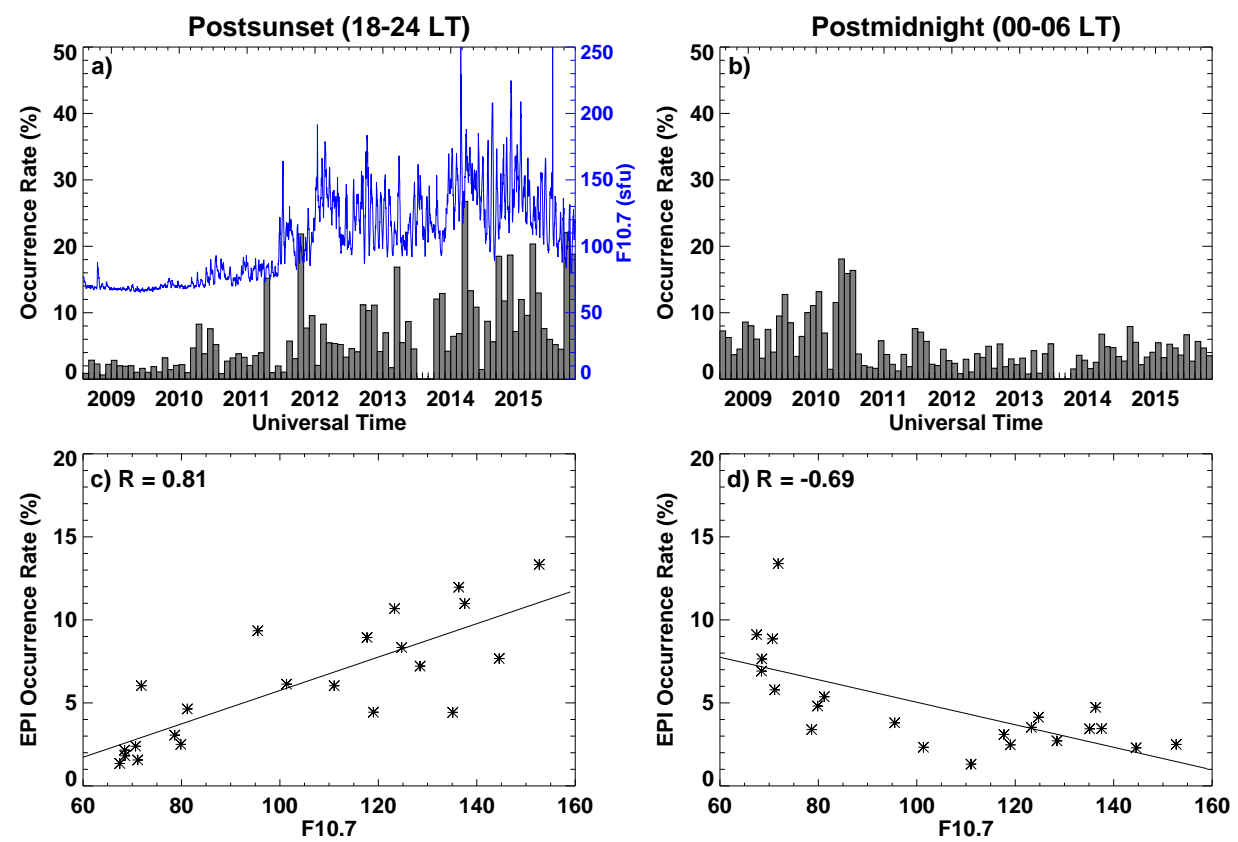

Figure 11. (a and b) Monthly variation of the postsunset/postmidnight EPI occurrence rate derived from C/NOFS in-situ ion density during 2008-2015. The temporal variation of daily F10.7 index is alos plotted. The gap in data during 2013 is the period when the satellite was placed into safe mode.(c and d) Scatter plots of the four-month average F10.7 index versus the EPI occurrence rate. $\mathrm{EPI}=$ equatorial plasma irregularity. $\mathrm{C} / \mathrm{NOFS}=$ Communications/Navigation Outage Forecasting System. 

Figure 2.
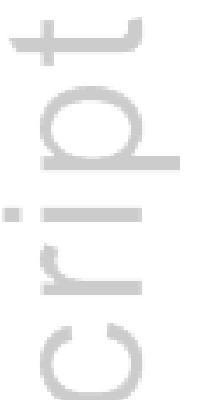

$\infty$
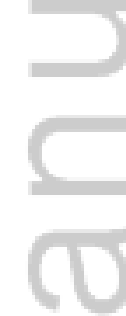

This article is protected by copyright. All rights reserved. 


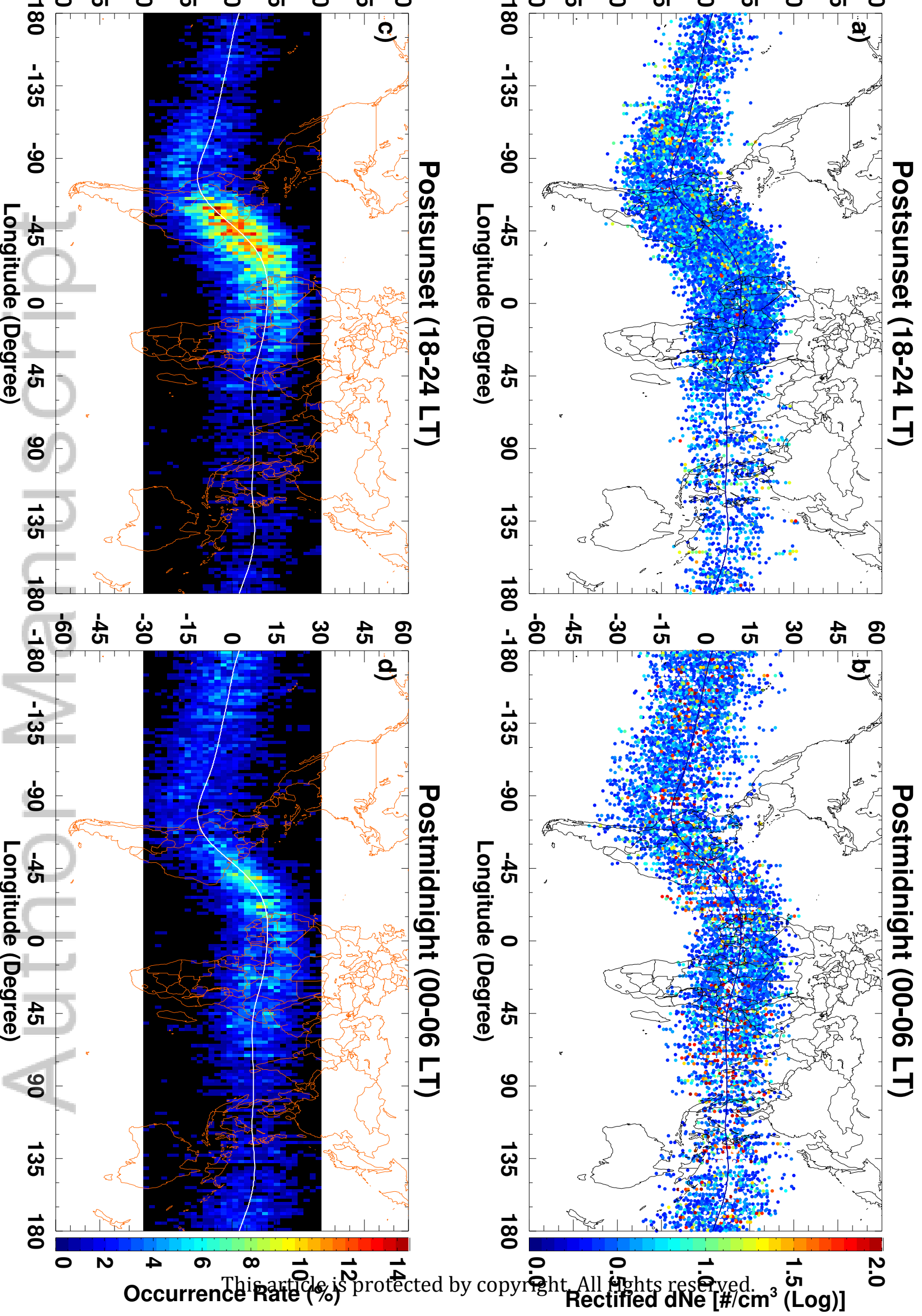





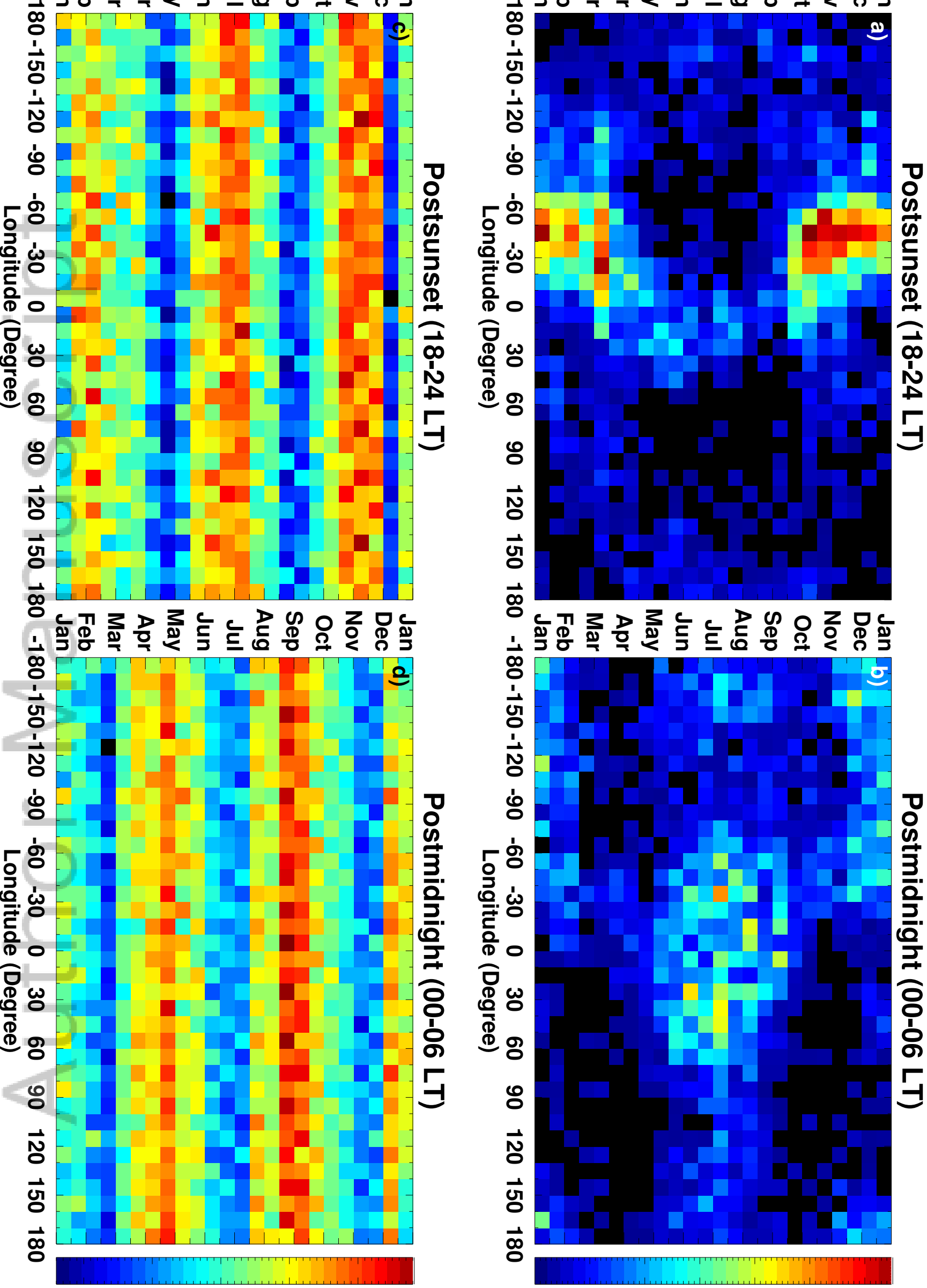

w $)$ girhis agicle is Swarm Crossing (\#) Occurrence Rate (\%) 
Figure 5.
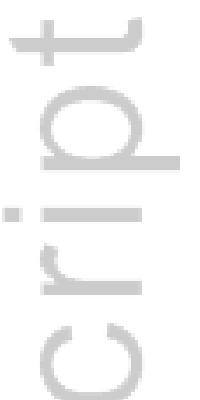

$\infty$
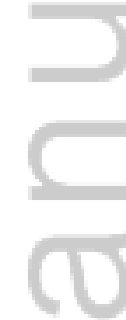

This article is protected by copyright. All rights reserved. 


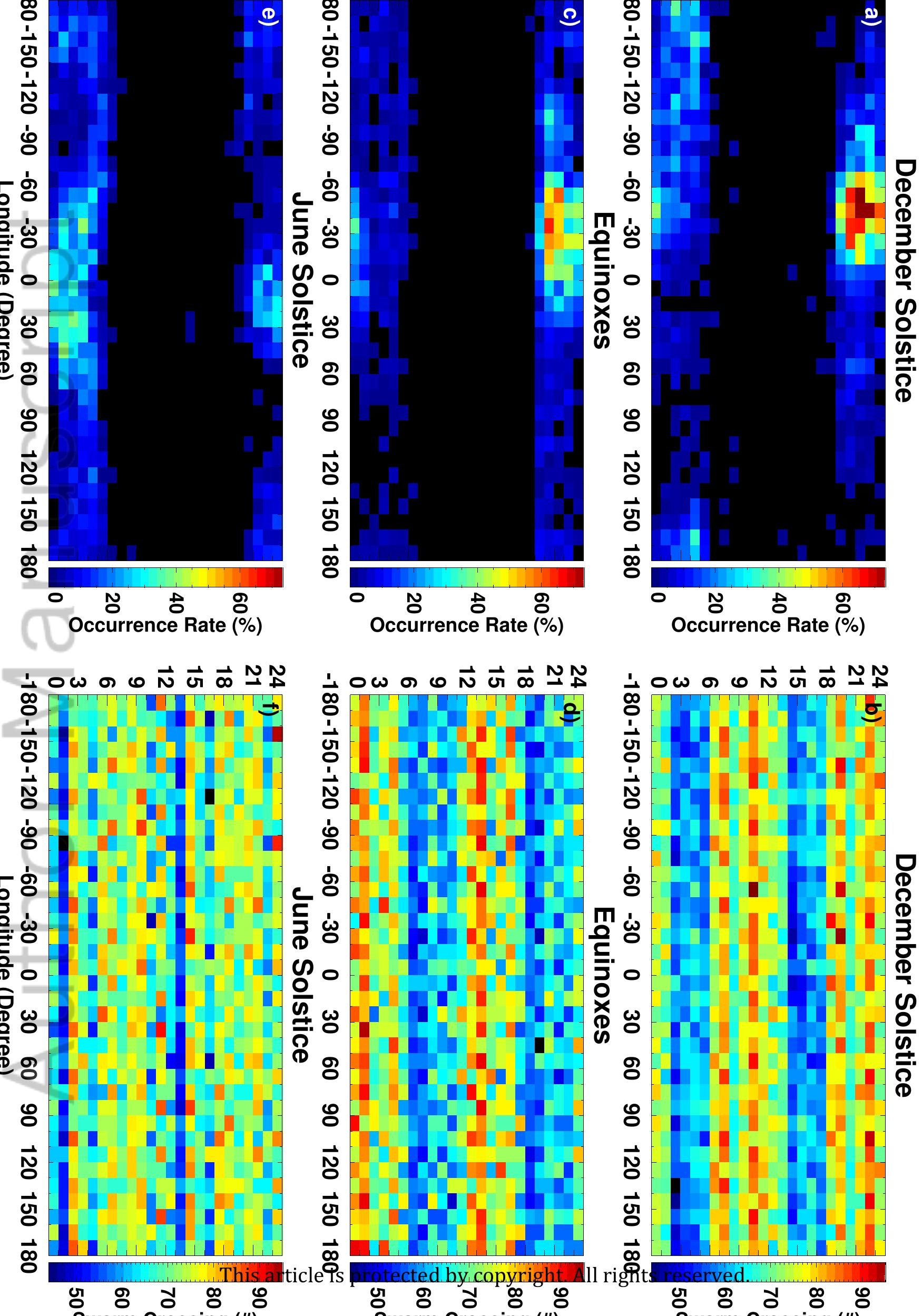

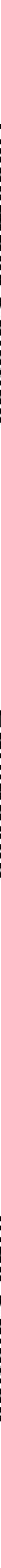

This article is protected by copyright. All rights reserved. 

Figure 9.
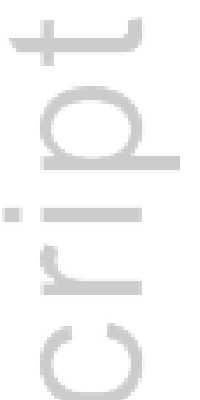

$\infty$
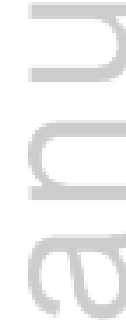

This article is protected by copyright. All rights reserved. 


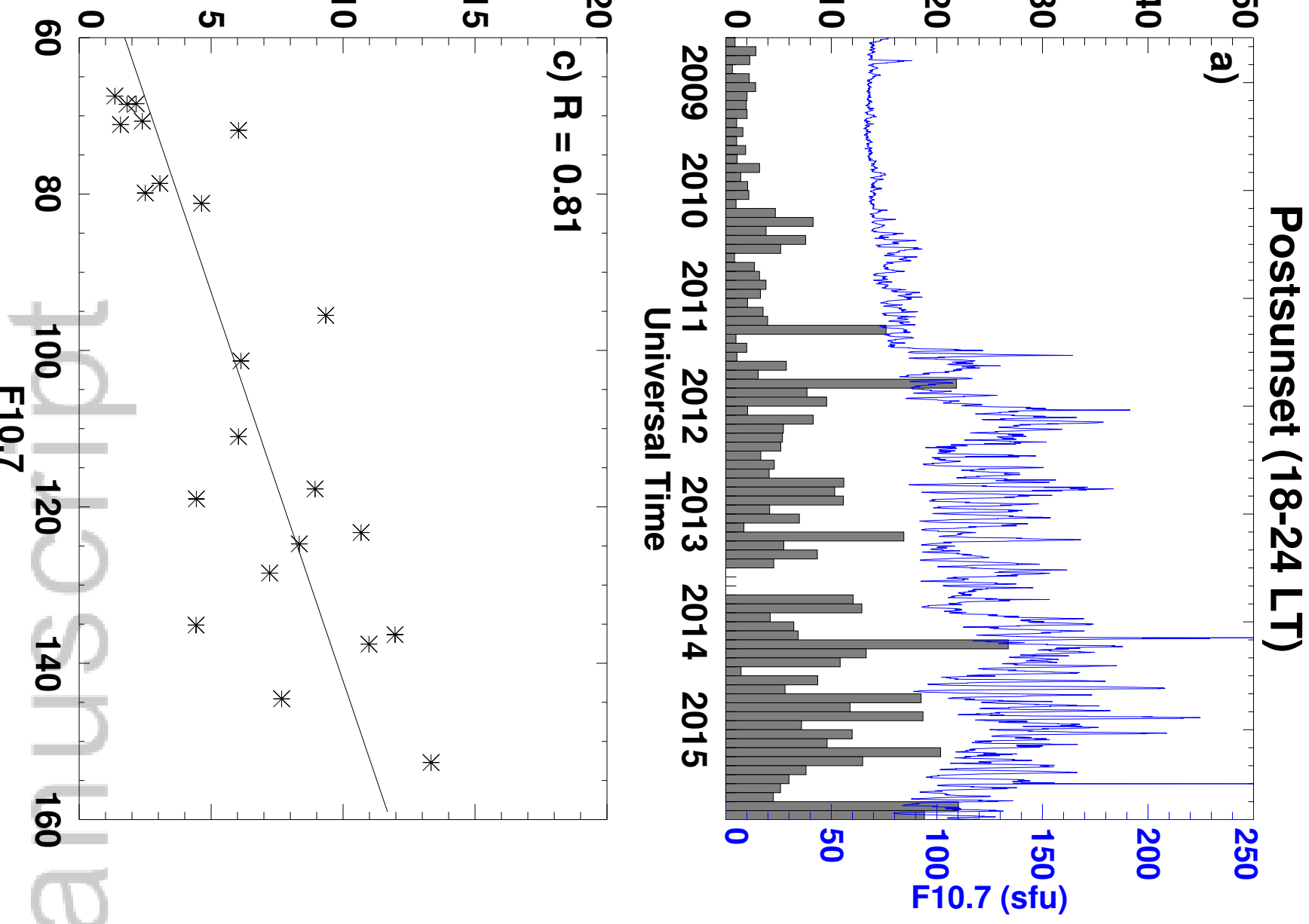

EPI Occurrence Rate (\%)

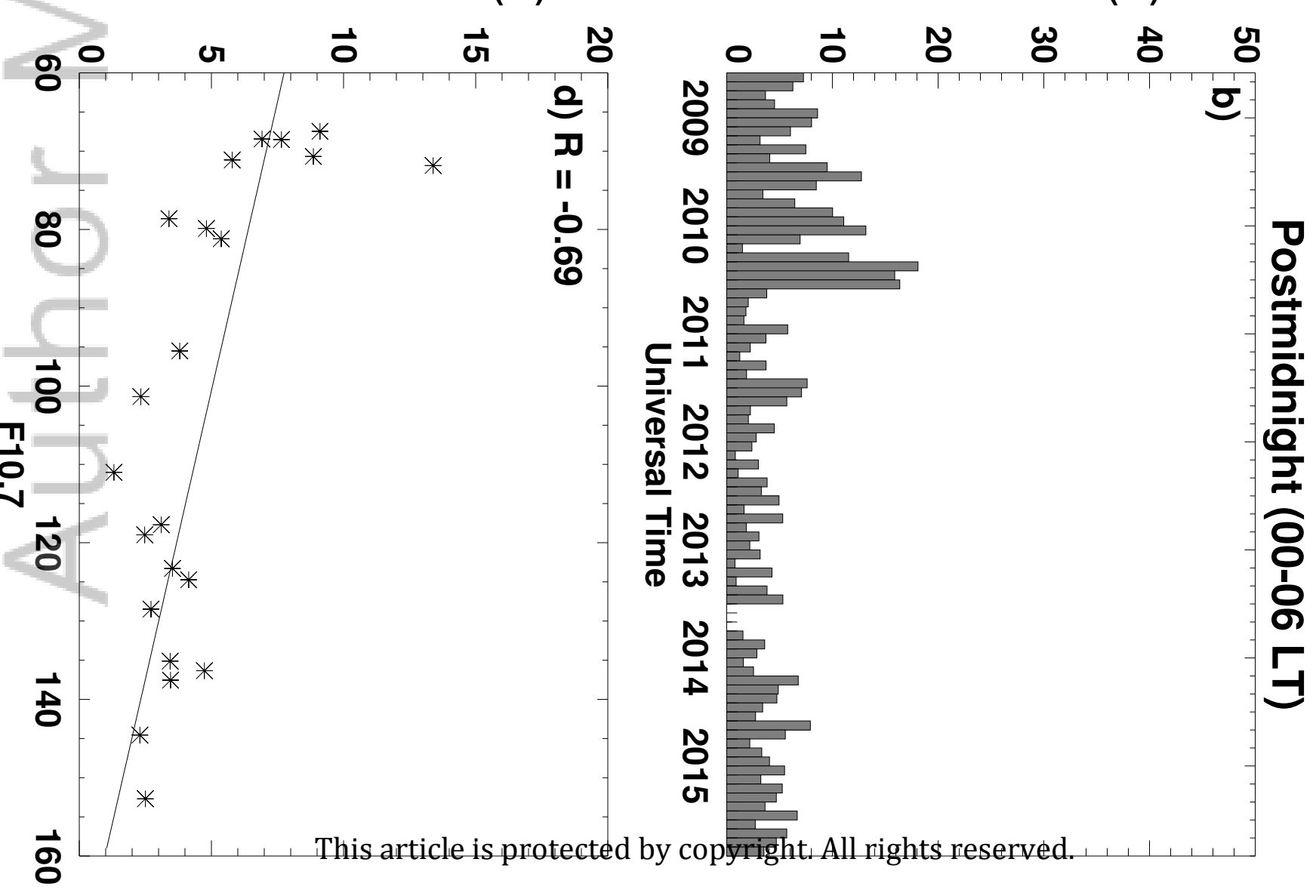



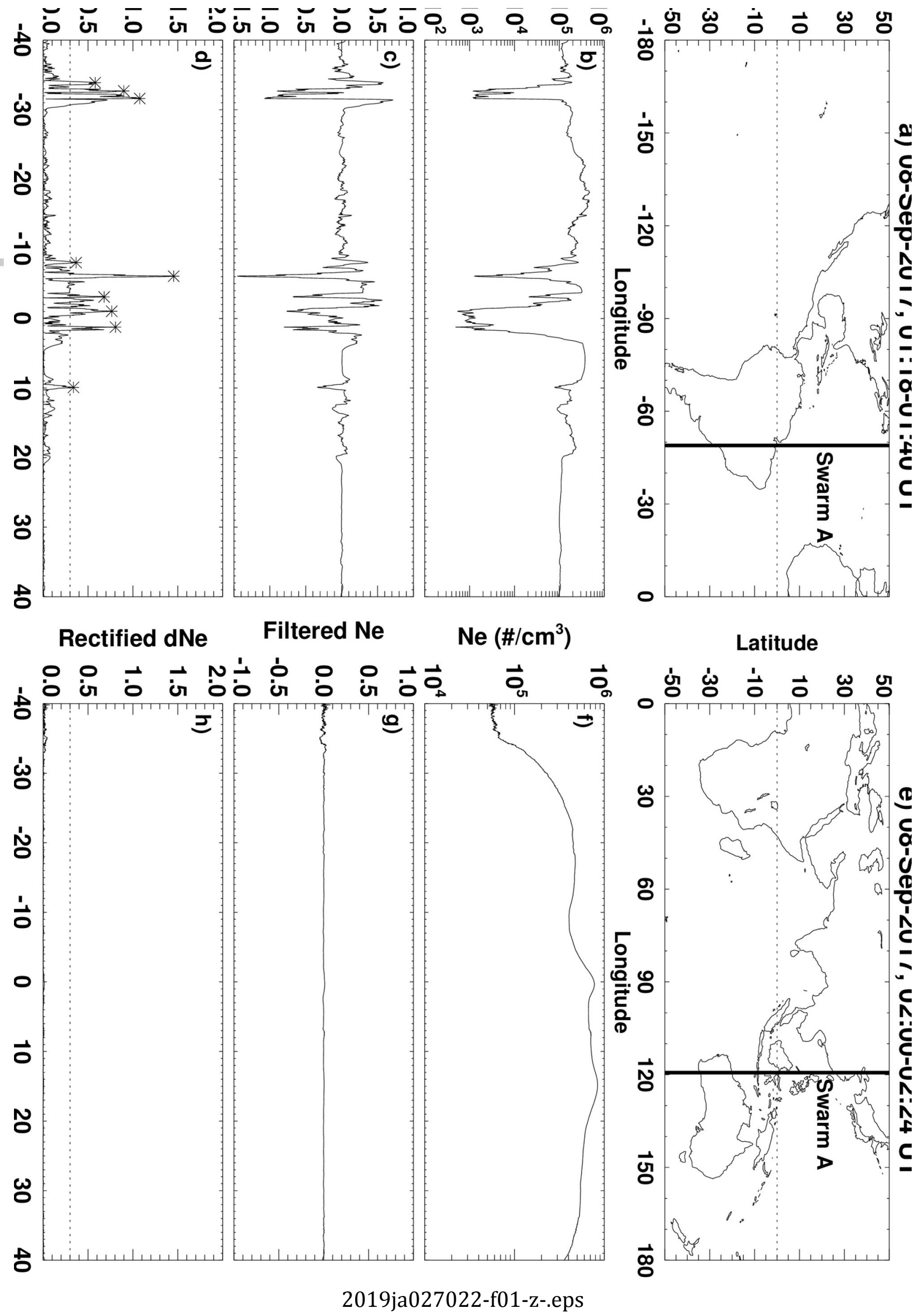

This article is protected by copyright. All rights reserved. 

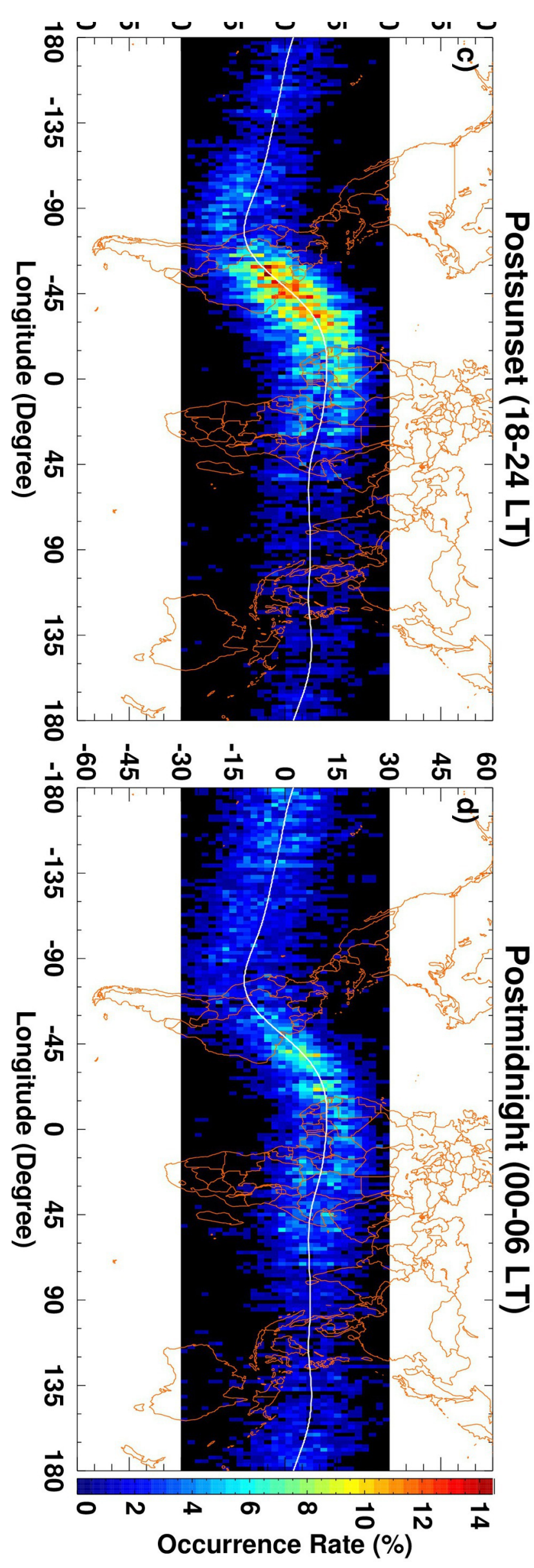
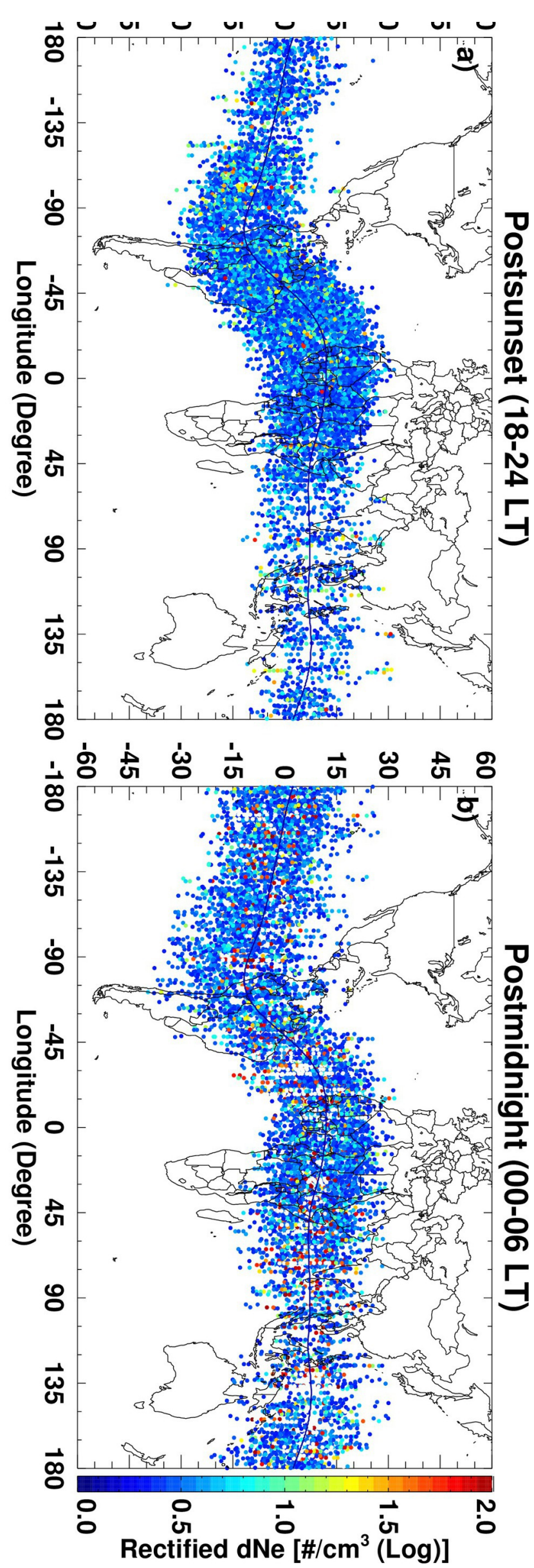

2019ja027022-f02-z-.eps 

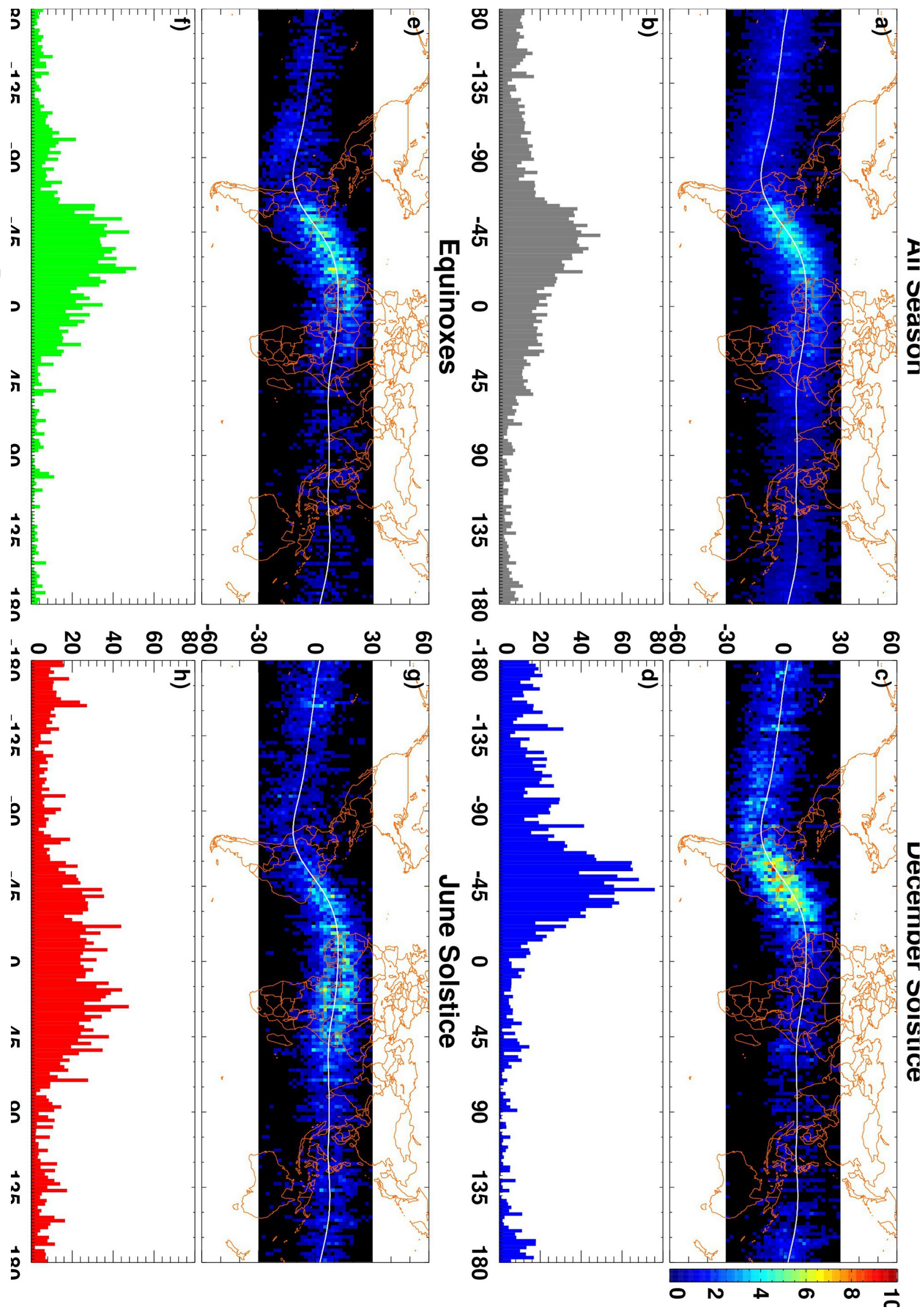

2019ja027022-f03-z-.eps 

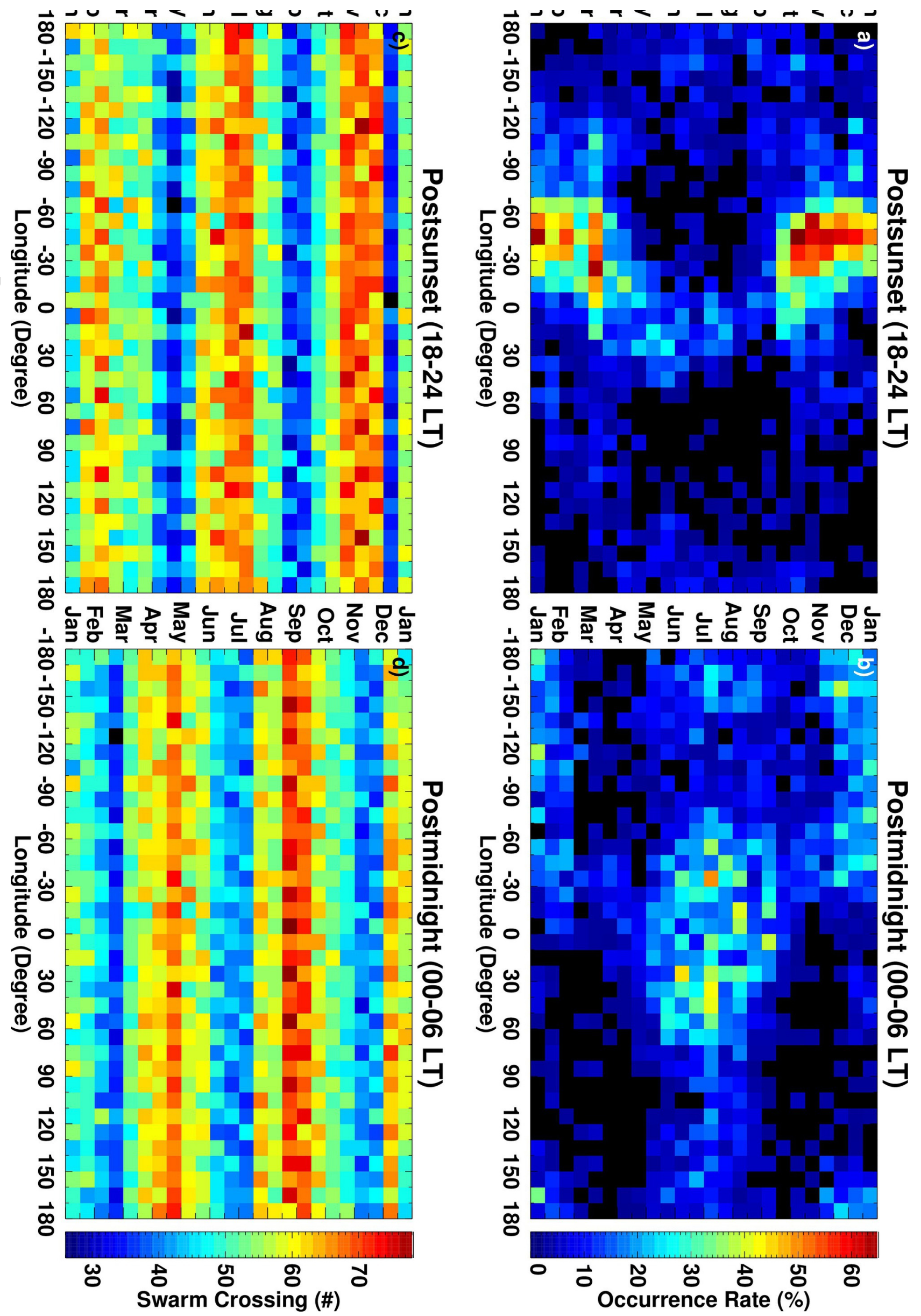

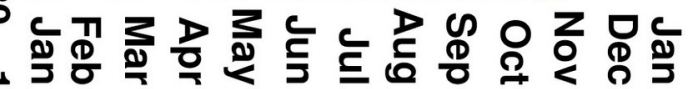
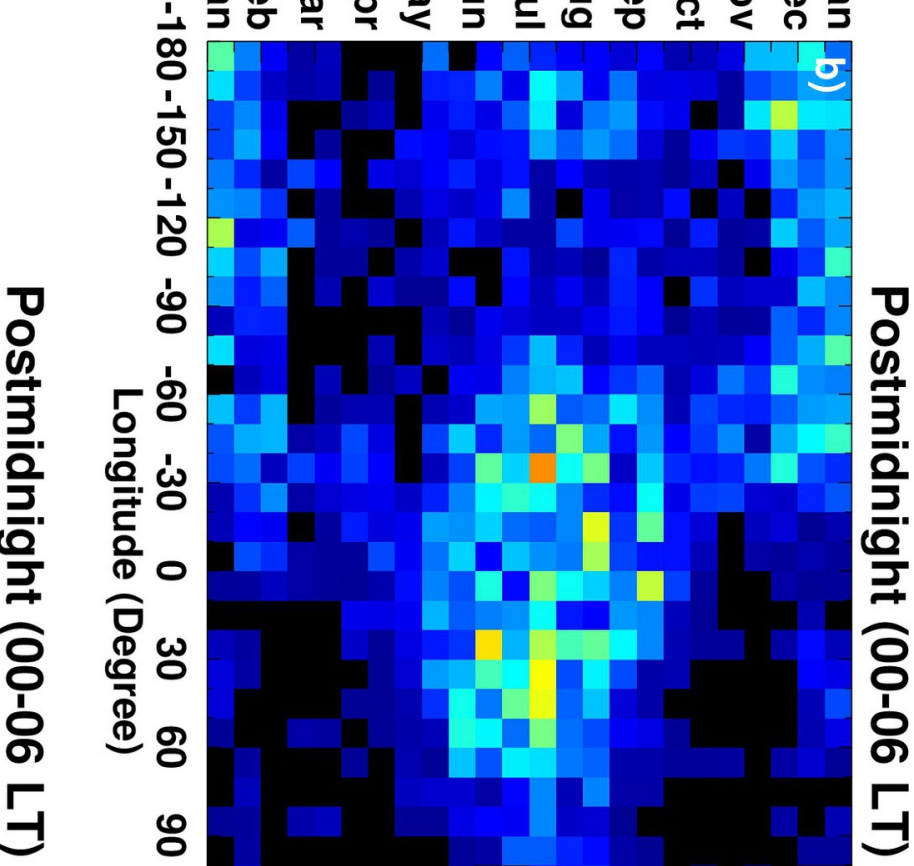

2019ja027022-f04-z-.eps 


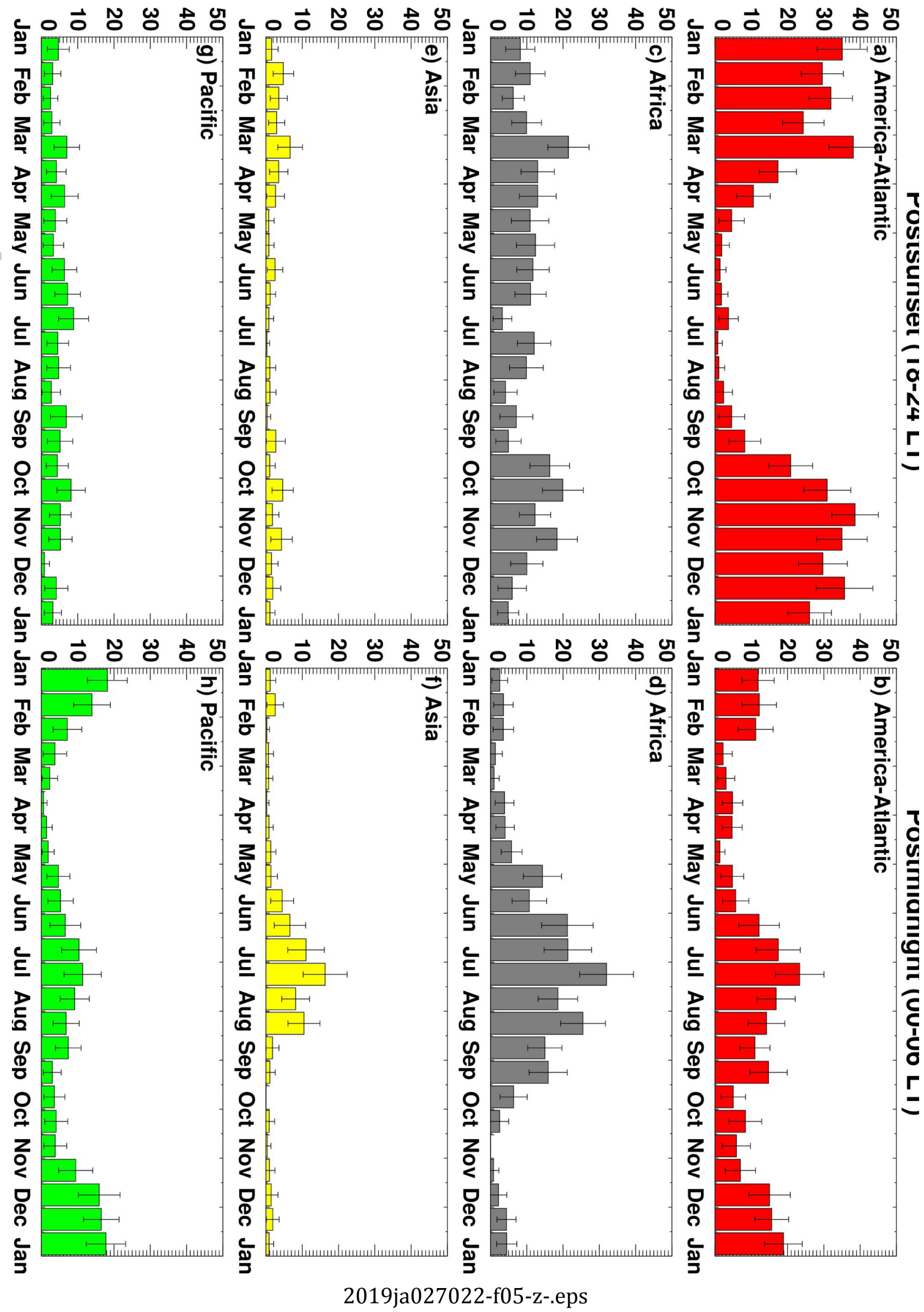

This article is protected by copyright. All rights reserved. 

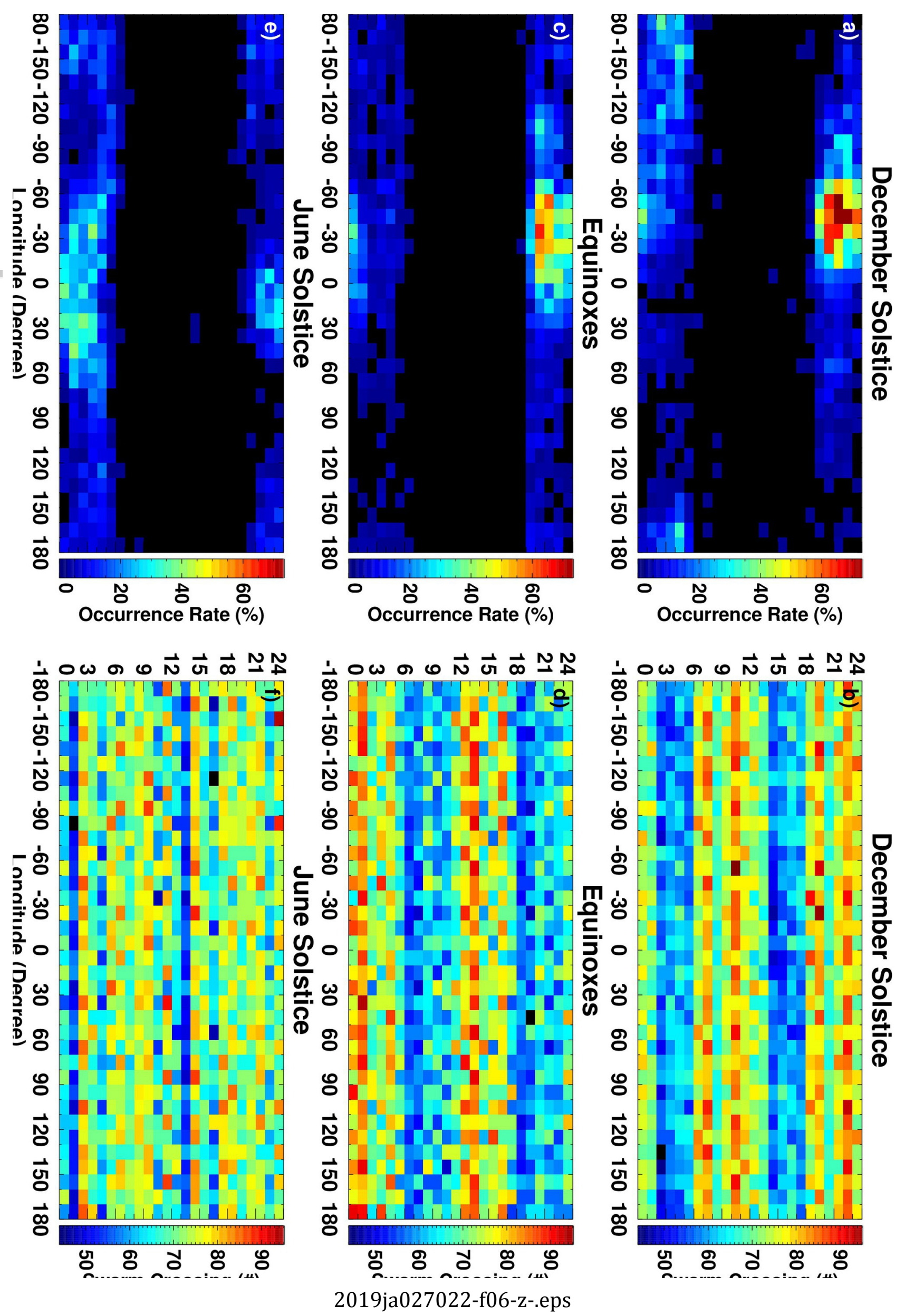


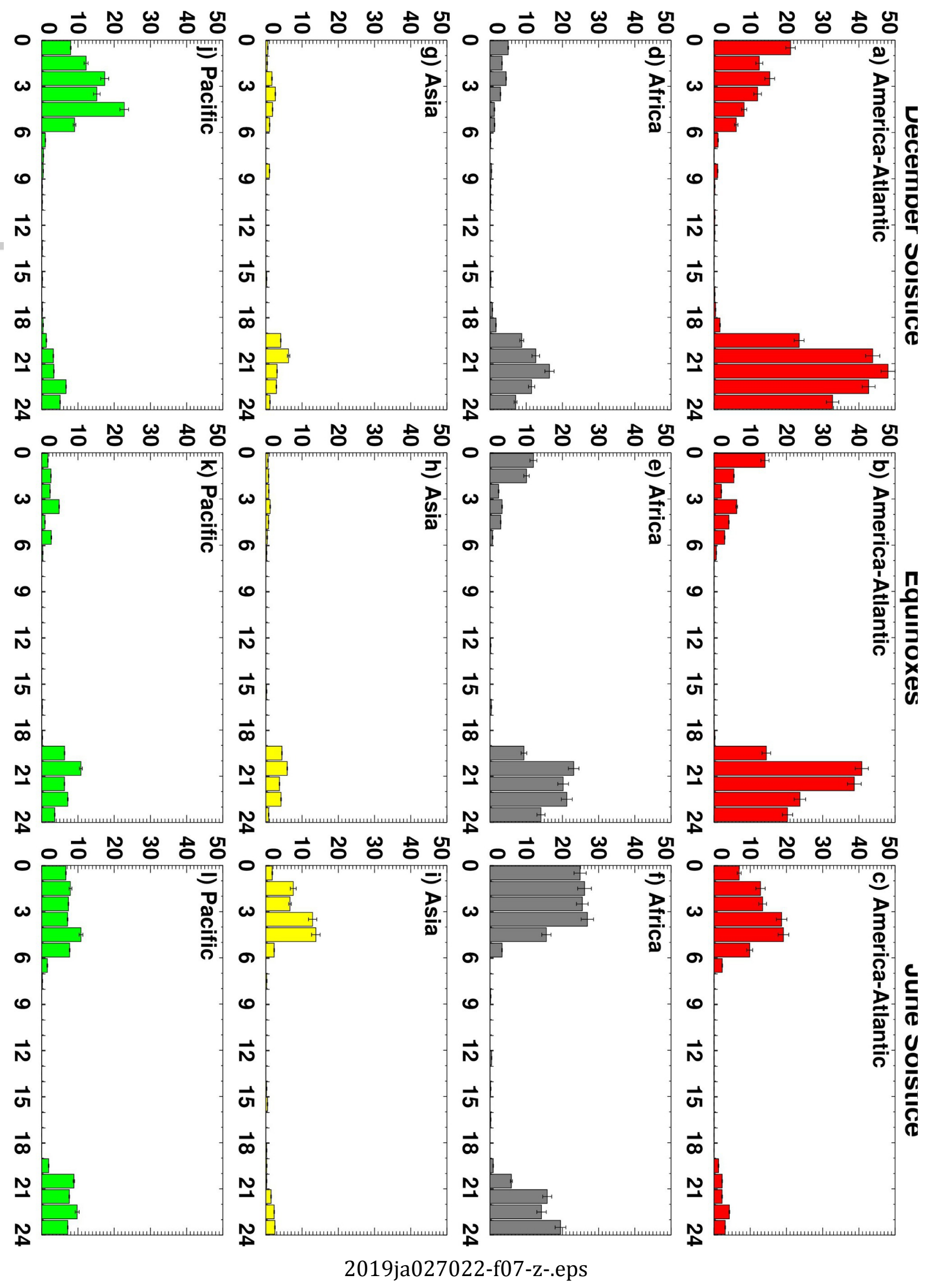

This article is protected by copyright. All rights reserved. 

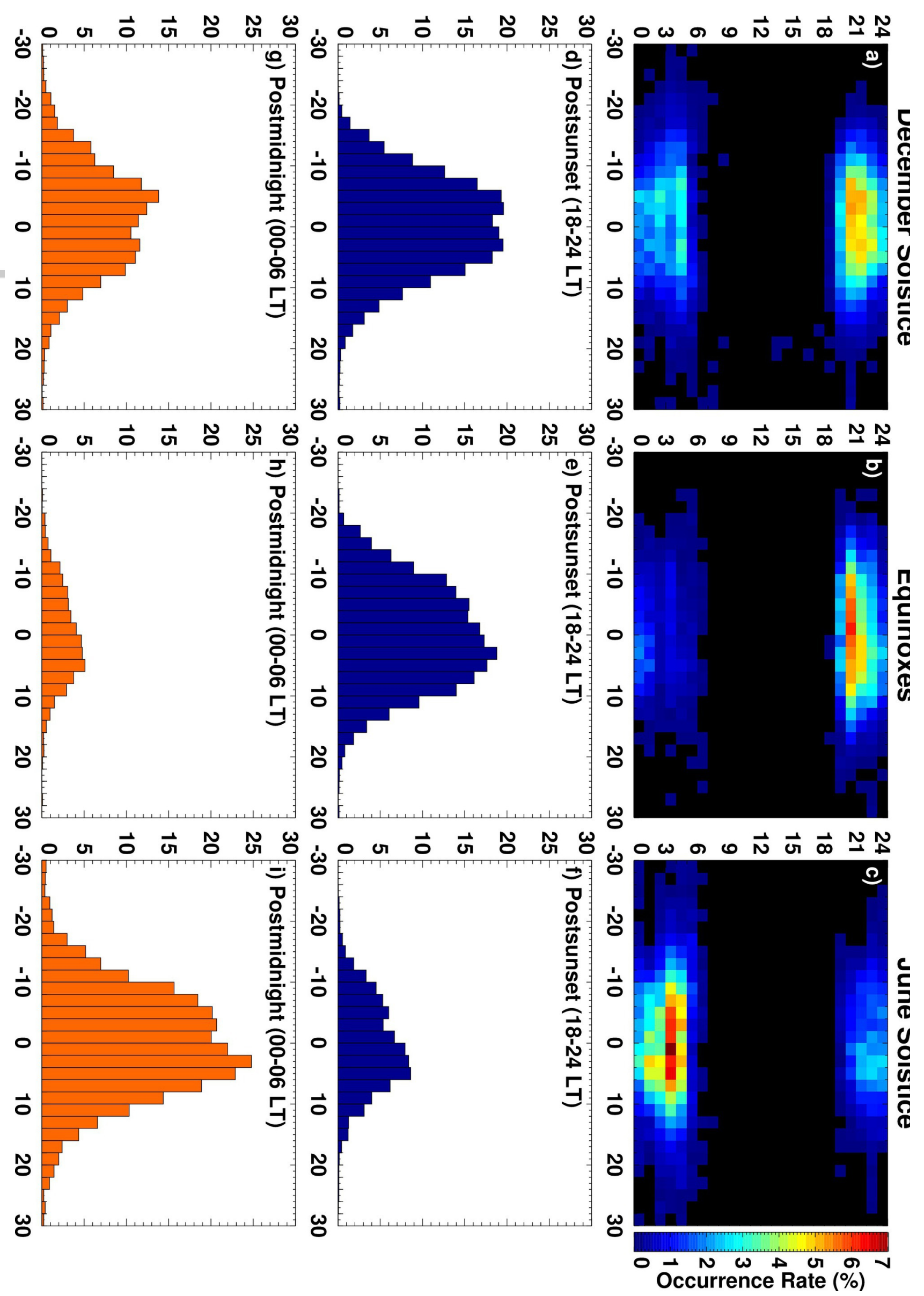

2019ja027022-f08-z-.eps 

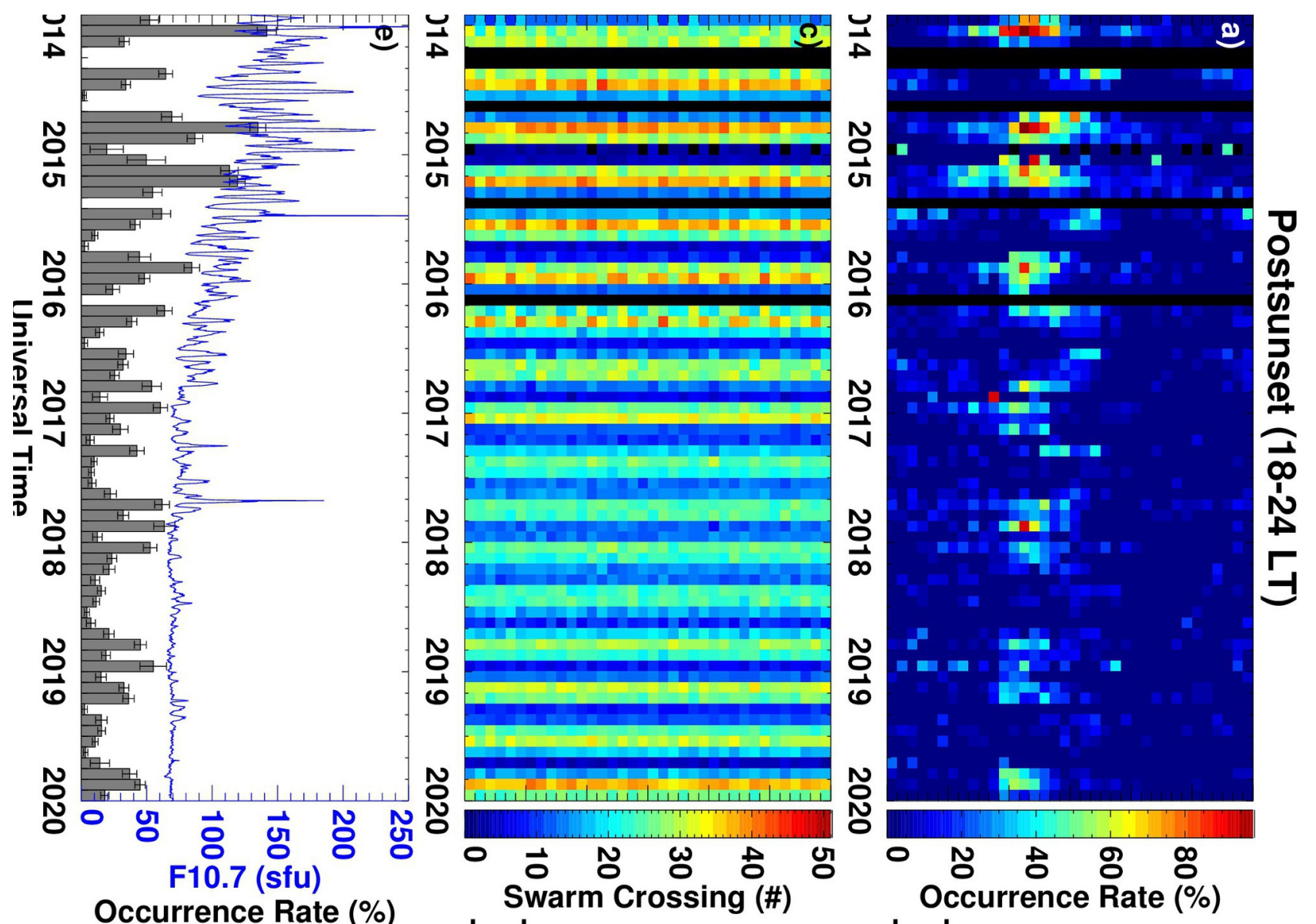

Occurrence Rate (\%)

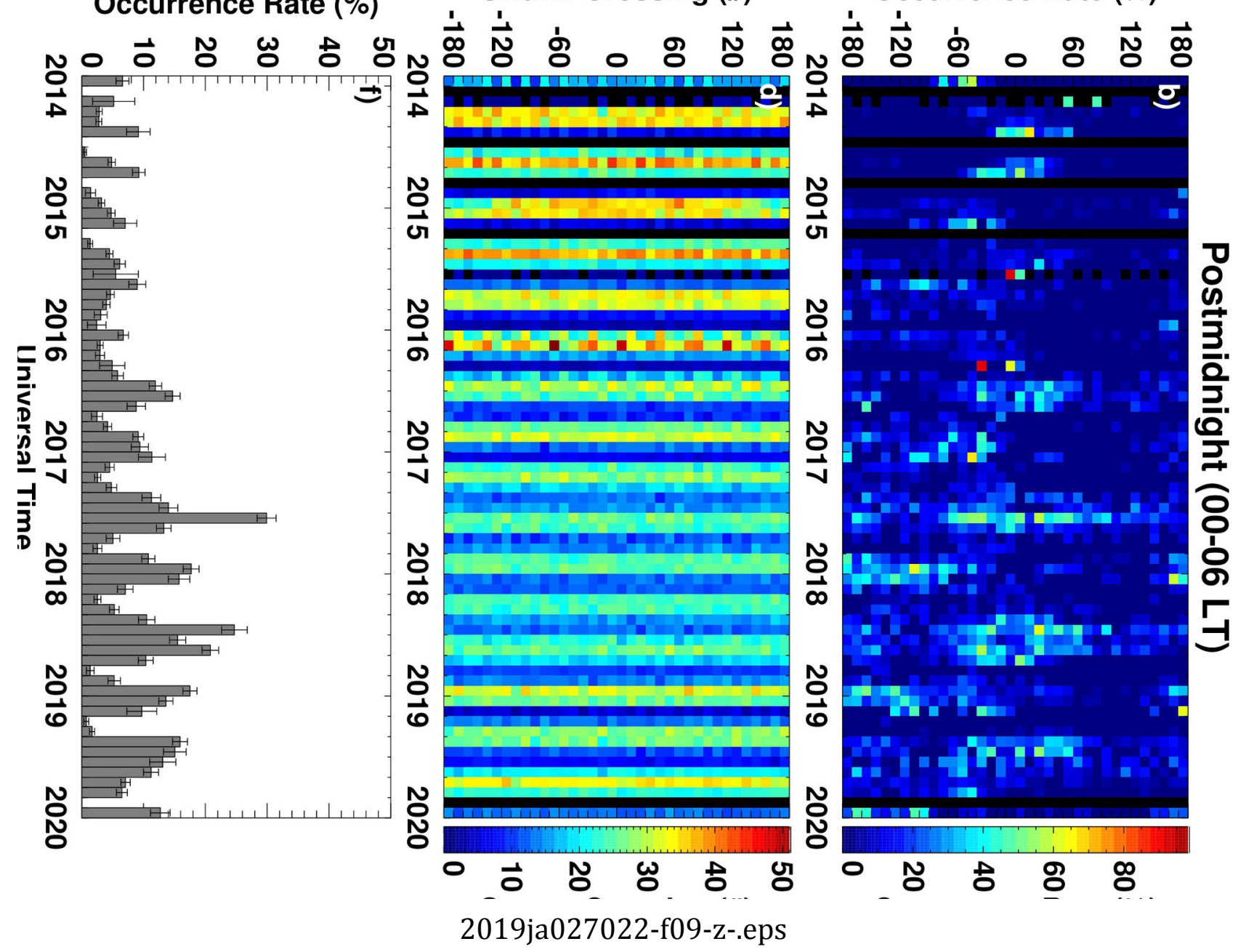

This article is protected by copyright. All rights reserved. 


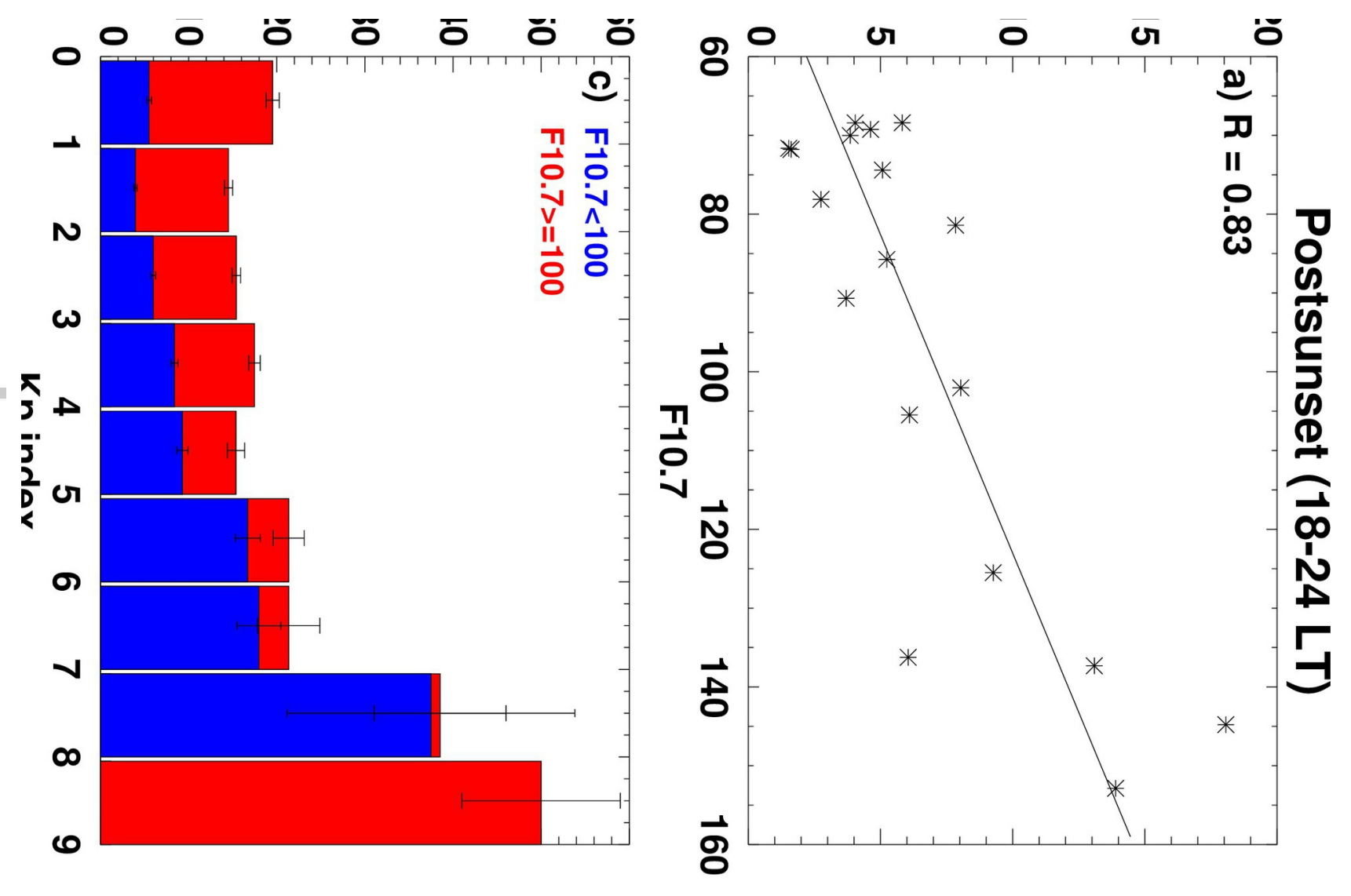

EPI Occurrence Rate (\%)

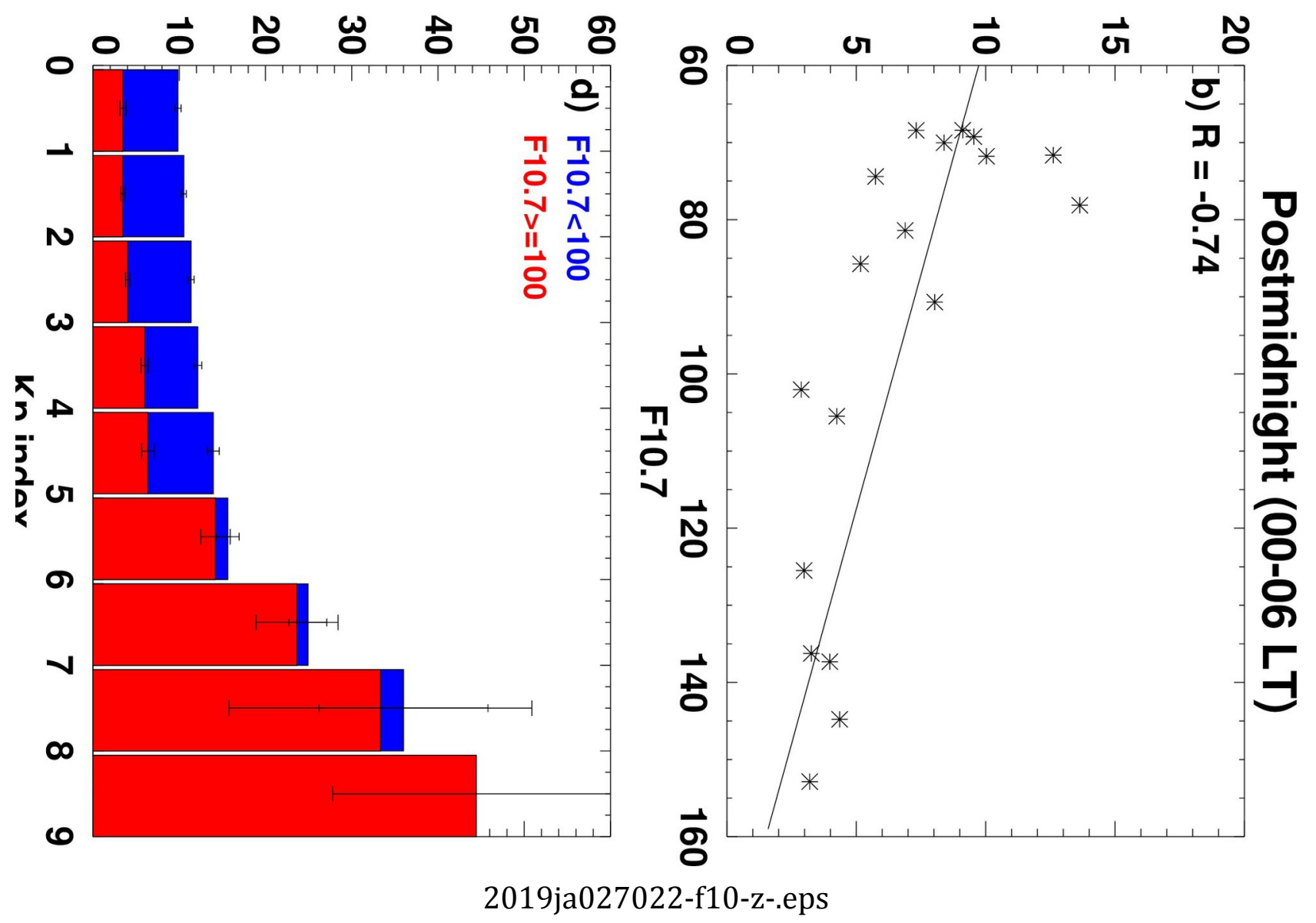

This article is protected by copyright. All rights reserved. 

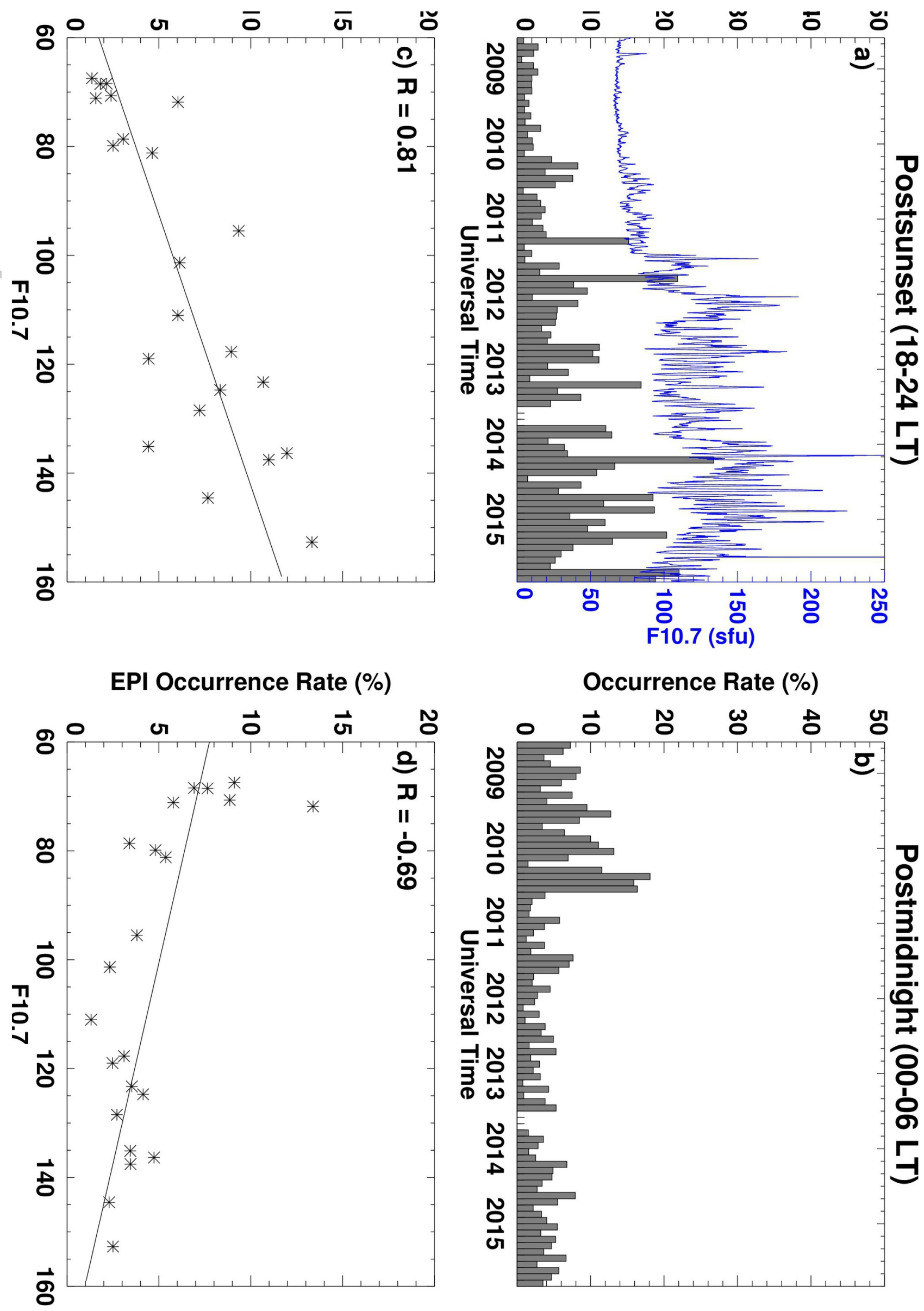

Occurrence Rate (\%)

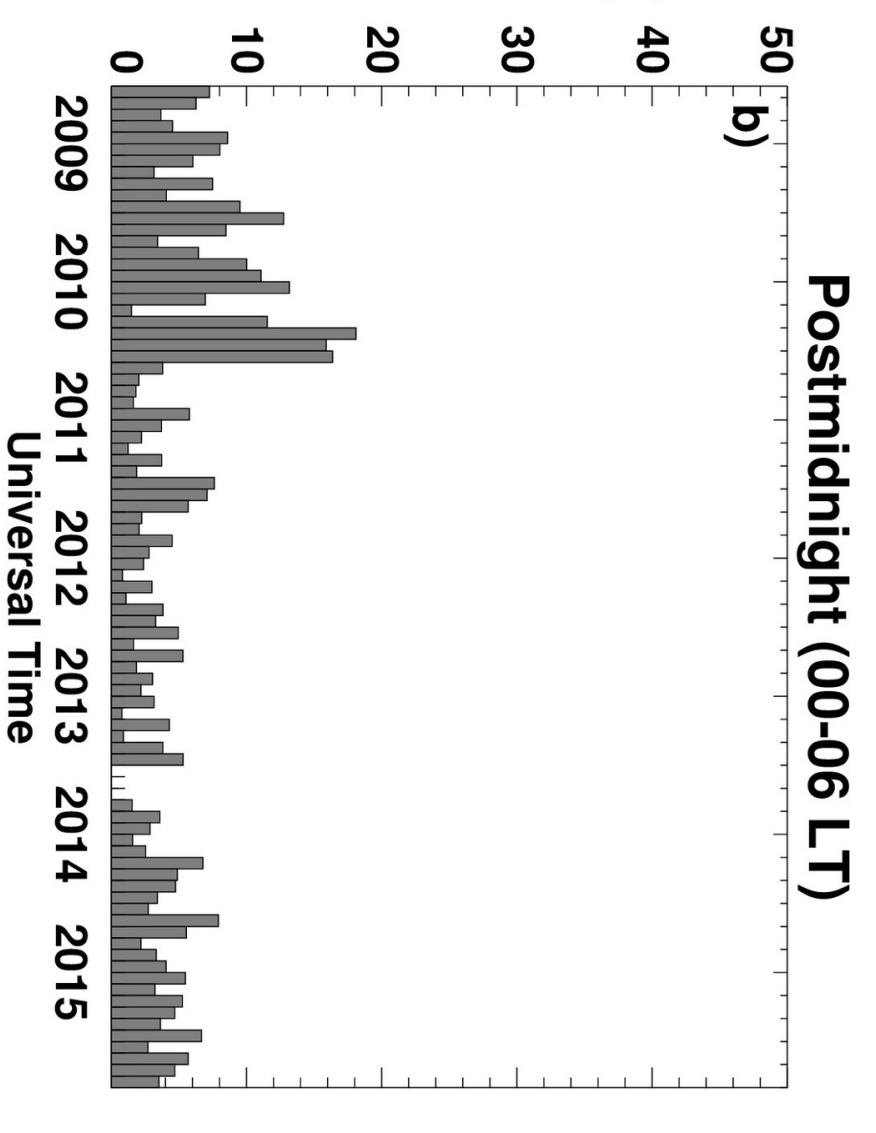

2019ja027022-f11-z-.eps

This article is protected by copyright. All rights reserved. 